PPPL-3281, Preprint: January 1998, UC-426

\title{
Synthesis of Ozone at Atmospheric Pressure by a Quenched Induction-Coupled Plasma Torch
}

\author{
B.C. Stratton 1, R. Knight ${ }^{2}$, and D.R. Mikkelsen 1 , \\ A. Blutke ${ }^{3}$, and J. Vavruska ${ }^{3}$
}

\author{
1Princeton Plasma Physics Laboratory, Princeton University, \\ Princeton, NJ 08543 \\ 2Drexel University, Center for the Plasma Processing of Materials, \\ Department of Materials Engineering, Philadelphia, PA \\ 3Plasma Technology, Inc., Santa Fe, NM
}

\begin{abstract}
The technical feasibility of using an induction-coupled plasma (ICP) torch to synthesize ozone at atmospheric pressure is explored. Ozone concentrations up to $\sim 250 \mathrm{ppm}$ were produced using a thermal plasma reactor system based on an ICP torch operating at $2.5 \mathrm{MHz}$ and $\sim 11 \mathrm{kVA}$ with an argon/oxygen mixture as the plasma-forming gas. A gaseous oxygen quench formed ozone by rapid mixing of molecular oxygen with atomic oxygen produced by the torch. The ozone concentration in the reaction chamber was measured by Fourier Transform infrared (FTIR) spectroscopy over a wide range of experimental configurations. The geometry of the quench gas flow, the quench flow velocity, and the quench flow rate played important roles in determining the ozone concentration. The ozone concentration was sensitive to the torch RF power, but was insensitive to the torch gas flow rates. These observations are interpreted within the framework of a simple model of ozone synthesis.
\end{abstract}

\section{Introduction}

The use of ozone in industrial processes is increasing. Applications for ozone include treatment of waste water, water purification and bleaching of paper in pulp mills, in all three cases as an alternative to toxic chlorine. Ozone cannot be stored, since it rapidly decomposes to oxygen, so it must be generated in-situ when required. Commercial ozonizers based on silent (dielectric barrier) discharges(1) are currently the most common method of ozone production. Low throughput, large physical size, and high electrical power consumption, however, make silent discharge ozonizers unattractive 
for many industrial applications. Thermal plasma jets, such as those produced by DC arcs or high frequency (RF) induction-coupled plasmas (ICP), may offer an attractive alternative route for ozone production. ICP torches are particularly attractive for ozone synthesis owing to the absence of the erodable refractory metal electrodes used in DC plasma torches, which oxidize very rapidly when used with oxygen-bearing plasma gases.

This paper presents the results of a study of the feasibility of ozone production using an ICP torch quenched with a gaseous oxygen flow. The paper is organized in the following way. Section 2 describes the fundamental chemistry of ozone production. The experimental apparatus, including the ICP torch, quench nozzles, and Fourier Transform infrared (FTIR) spectrometer used to measure the ozone concentration, is described in section 3. Section 4 presents the experimental results. The experimental results are summarized and a direction for further development of this technique is presented in section 5. Appendix 1 describes estimates of the gas temperature derived from FTIR spectroscopy measurements of rotational structure of a molecular vibrational band.

\section{Fundamentals of Ozone Formation}

The three essential elements of ozone synthesis are: 1) the formation of atomic oxygen; 2) its reaction with molecular oxygen to form ozone, and 3) some means of minimizing the destruction of the newly formed ozone(1-3). In conventional ozonizers based on dielectric barrier discharges, atomic oxygen is produced by electron impact dissociation in an electrical discharge in air or molecular oxygen, and it promptly reacts with ambient molecular oxygen. Thermal decomposition of ozone is minimized by maintaining the temperature below $\sim 400 \mathrm{~K}$.

The approach taken here used a plasma torch to generate atomic oxygen by thermal dissociation at temperatures above $4000 \mathrm{~K}$. Ozone synthesis then took place as the torch jet was mixed with and cooled by a stream of colder gaseous oxygen. This quench gas minimized ozone destruction by diluting the atomic oxygen flowing from the torch and by cooling the resulting ozone/oxygen mixture.

Ozone synthesis has been extensively studied and many reaction pathways have been considered in analyses of ozone production by dielectric barrier discharges $(2)$. The most important processes in the reaction chamber used in our experiments were expected to be:

$$
\mathrm{O}+\mathrm{O}+\mathrm{M} \rightarrow \mathrm{O}_{2}+\mathrm{M}
$$




$$
\begin{aligned}
\mathrm{O}+\mathrm{O}_{2}+\mathrm{M} & \rightarrow \mathrm{O}_{3}+\mathrm{M} \\
\mathrm{O}_{3}+\mathrm{M} & \rightarrow \mathrm{O}+\mathrm{O}_{2}+\mathrm{M} \\
\mathrm{O}+\mathrm{O}_{3} & \rightarrow 2 \mathrm{O}_{2}
\end{aligned}
$$

Recombination by reaction $\mathrm{R} 1$ represents the main loss channel for $\mathrm{O}$ when $\mathrm{T}>1200 \mathrm{~K}$ and when $[\mathrm{O}] /\left[\mathrm{O}_{2}\right] \geq 0.1$ for temperatures as low as $500 \mathrm{~K}$. At lower temperatures most $\mathrm{O}$ will be converted quickly to $\mathrm{O}_{3}$ by reaction $\mathrm{R} 2$. The back reaction, $\mathrm{R} 3$, maintains a small concentration of $\mathrm{O}$, which reduces the ozone concentration via reaction $\mathrm{R} 4$ (destroying both $\mathrm{O}$ and $\mathrm{O}_{3}$ ). This will be the dominant loss channel for $\mathrm{T}<1000 \mathrm{~K}$, and will reduce the ozone concentration to $100 \mathrm{ppm}$ in less than a second unless $\mathrm{T} \leq 550 \mathrm{~K}$. Previous work $(2)$ showed that the efficiency of ozone formation was high only if $[\mathrm{O}] /\left[\mathrm{O}_{2}\right] \leq 10^{-3}$ initially and $\mathrm{T}<700 \mathrm{~K}$. With higher initial levels of atomic oxygen reaction $\mathrm{R} 4$ unavoidably reduces the conversion efficiency.

Using $\mathrm{O}_{2}$ quench gas at a temperature of $\sim 300 \mathrm{~K}$ to dilute $\mathrm{O}$ in the torch jet to a relative concentration less than $3 \times 10^{-3}$ will reduce the final temperature of the mix below $400 \mathrm{~K}$. If this can be accomplished rapidly enough the oxygen will be converted to ozone with high efficiency. Using a higher initial oxygen concentration of $10^{-2}$ raises the final temperature and reduces the ideal efficiency to $25 \%$, but the efficiency can be raised to $\sim 60 \%$ by using a liquid oxygen quench to lower the final temperature. In single stage synthesis the practical limit of ozone concentration is therefore $\sim 1 \%$. Multi-stage syntheses using quench gas containing ozone produced in previous stages could raise the ozone concentration, but the strong temperature dependence of ozone decomposition would make this less effective with a plasma torch than in 'cold' electrostatic ozonizers.

Rapid mixing of the plasma jet and the quench gas is therefore critical in four ways: 1) to prevent recombination of the $\mathrm{O}$ atoms, 2) to mix $\mathrm{O}$ and $\mathrm{O}_{2}$ so that ozone can be formed, 3) to dilute the atomic oxygen concentration in order to minimize the destruction reactions $\mathrm{R} 3$ and $\mathrm{R} 4$, and 4) to cool the mixture below $500 \mathrm{~K}$ to prevent thermal decomposition of the ozone.

Estimates of the required mixing time scales can be derived from the rates of change of $[\mathrm{O}]$ and $\left[\mathrm{O}_{2}\right]$ in a bath of $\mathrm{O}_{2}$ :

$$
\frac{\mathrm{d}[\mathrm{O}]}{\mathrm{dt}}=-\mathrm{k}_{2}[\mathrm{O}]\left[\mathrm{O}_{2}\right]^{2}+\mathrm{k}_{3}\left[\mathrm{O}_{3}\right]\left[\mathrm{O}_{2}\right]-\mathrm{k}_{4}[\mathrm{O}]\left[\mathrm{O}_{3}\right]-2 \mathrm{k}_{1}[\mathrm{O}]^{2}\left[\mathrm{O}_{2}\right]
$$




$$
\left.\frac{\mathrm{d}[\mathrm{O}}{\mathrm{dt}} 3\right]=+\mathrm{k}_{2}[\mathrm{O}]\left[\mathrm{O}_{2}\right]^{2}-\mathrm{k}_{3}\left[\mathrm{O}_{3}\right]\left[\mathrm{O}_{2}\right]-\mathrm{k}_{4}[\mathrm{O}]\left[\mathrm{O}_{3}\right]
$$

Rate constants for reactions R1 and R3 were taken from Eliasson and Kogelschatz(4), and those for reactions $\mathrm{R} 2$ and $\mathrm{R} 4$ were fits to the NIST chemical kinetics database(5):

$$
\begin{aligned}
& \mathrm{k}_{1}=4.8 \times 10^{15}(300 / \mathrm{T}) \exp (-170 / \mathrm{T}) \mathrm{cm}^{6} / \mathrm{mole}^{2}{ }_{-\mathrm{s}} \\
& \mathrm{k}_{2}=9 \times 10^{13}(298 / \mathrm{T})^{1.52} \exp (+205 / \mathrm{T}) \mathrm{cm}^{6} / \mathrm{mole}^{2}-\mathrm{s} \\
& \mathrm{k}_{3}=4.4 \times 10^{14} \exp (-11400 / \mathrm{T}) \mathrm{cm}^{3} / \mathrm{mole}-\mathrm{s} \\
& \mathrm{k}_{4}=7.3 \times 10^{12} \exp (-2125 / \mathrm{T}) \mathrm{cm}^{3} / \mathrm{mole}-\mathrm{s}
\end{aligned}
$$

While reactions $\mathrm{R} 3$ and $\mathrm{R} 2$ can interchange $\mathrm{O}_{3}$ and $\mathrm{O}$ at a rapid rate, they only convert ozone into 'potential ozone' and back again; the real loss rate is obtained by summing the individual rates:

$$
\frac{\mathrm{d}[\mathrm{O}+\mathrm{O}}{\mathrm{dt}} 3^{2}=-2 \mathrm{k}_{4}[\mathrm{O}]\left[\mathrm{O}_{3}\right]-2 \mathrm{k}_{1}[\mathrm{O}]^{2}\left[\mathrm{O}_{2}\right]
$$

which can be much smaller than the individual rates for reactions R2 and R3. The characteristic time scale for $\left[\mathrm{O}+\mathrm{O}_{3}\right]$ destruction is

$$
\tau_{\mathrm{des}}=\left\{2\left[\mathrm{O}+\mathrm{O}_{3}\right]\left(\mathrm{k}_{4}\left(1-f_{3}\right) f_{3}+\mathrm{k}_{1}\left(1-f_{3}\right)^{2}\left[\mathrm{O}_{2}\right]\right)\right\}^{-1}
$$

where $f_{3}=\left[\mathrm{O}_{3}\right] /\left[\mathrm{O}+\mathrm{O}_{3}\right]$. Note that $\tau_{\mathrm{des}}$ is proportional to the inverse of $\left[\mathrm{O}+\mathrm{O}_{3}\right]$ and therefore increases as destruction proceeds.

Solving Eqs. 1 and 2 with the initial conditions $[\mathrm{O}]=\left[\mathrm{O}_{\mathrm{i}}\right.$ and $\left[\mathrm{O}_{3}\right]=0$, it is found that $\left[\mathrm{O}_{3}\right]$ rises rapidly to a peak value, at which time $[\mathrm{O}]+\left[\mathrm{O}_{3}\right] \approx[\mathrm{O}]_{\mathrm{i}}$, and then both $[\mathrm{O}]$ and $\left[\mathrm{O}_{3}\right]$ decay relatively slowly.

The destruction time scale can be estimated by evaluating Eq. 4 using the value of $f_{3}$ at the time of peak $\left[\mathrm{O}_{3}\right]$. In steady state, Eq. 2 becomes a quadratic equation for $f_{3}$ which always has one physical root with $0<f_{3}<1$. The behavior of $f_{3}$ with temperature is shown in Fig. 1 for different values of $\left[\mathrm{O}+\mathrm{O}_{3}\right] /\left[\mathrm{O}_{2}\right]$. Note that $f_{3} \approx 1$ at low temperatures and $f_{3} \approx 0$ at high temperatures, with a relatively narrow transition in the region $400<\mathrm{T}<1000 \mathrm{~K}$. The location of the transition varies because the term $\mathrm{k}_{4}\left[\mathrm{O}_{[}\left[\mathrm{O}_{3}\right]\right.$ becomes important for high $\left[\mathrm{O}+\mathrm{O}_{3}\right]$. The resulting $\tau_{\mathrm{des}}$, plotted versus temperature in Fig. 2, varies roughly as the inverse of $\left[\mathrm{O}+\mathrm{O}_{3}\right]$, but the dependence for $\mathrm{T}<1000$ $\mathrm{K}$ is more complicated because $f_{3}$ depends on $\left[\mathrm{O}+\mathrm{O}_{3}\right]$ as well as temperature. 
Boulos and Ye have generously provided a two-dimensional computer simulation of our standard plasma torch condition(6). Briefly, their mathematical model assumed the plasma to be in local thermodynamic equilibrium, and Boussinesq's model of eddy viscosity was used to model the mixing of argon and oxygen in the plasma torch. Details of the computer model and comparisons with experimental data can be found in Rahamane, et al.(7) and references therein. The spatial distributions of the temperature, flow speed, and atomic species concentration calculated for our torch were similar to those shown in reference 7 . At the exit of the torch and in the quench region, the simulation predicted that the argon and oxygen would be well mixed, that the maximum temperature dropped to $\sim 4000 \mathrm{~K}$, and that the peak flow speed was $\sim 20 \mathrm{~m} / \mathrm{s}$. The atomic oxygen concentration was large inside a column of $\sim 30 \mathrm{~mm}$ diameter: $[\mathrm{O}] /\left[\mathrm{O}_{2}\right] \approx 1$ in the center of the column and it fell rapidly to $10^{-2}-10^{-4}$ outside a radius of $\sim 15 \mathrm{~mm}$.

Cooling and dilution of the torch jet by the quench gas was accomplished by turbulent mixing in the reaction chamber. Cooling the entire torch output by mixing would require a quench flow rate of $\sim 10^{3} \mathrm{slm}$. In most cases a small quench jet was used which entrained only a small part of the torch flow; the bulk of the thermal output of the torch was dissipated to the watercooled reaction chamber walls downstream from the observation region.

Mixing of the torch and quench flows is a highly stochastic process, with different portions of the gas mixing much more rapidly or slowly than the average. The typical mixing time scale of turbulent eddies is simply $L / v$, where $L$ is the diameter of the turbulent jet and $v$ is the flow speed of the jet(8). For a high speed quench jet directed across the plasma jet produced by the torch, the flow speed near the quench jet orifice will be in the range 100$300 \mathrm{~m} / \mathrm{s}$, but where the quench flow emerges from the high temperature region it is considerably expanded and moves much more slowly. Note, however, that if the emerging quench flow has a diameter of $\sim 10 \mathrm{~mm}$ then a flow speed of only $10 \mathrm{~m} / \mathrm{s}$ is sufficient to produce a mixing time of $\sim 10^{-3} \mathrm{~s}$, which prevents the decline of $\left[\mathrm{O}+\mathrm{O}_{3}\right] /\left[\mathrm{O}_{2}\right]$ below $\sim 10^{-4}$ (see Fig. 2). For a quench supplied through a large distant opening in the reaction chamber the plasma torch jet velocity drives the mixing. The length scale will be larger and the flow speeds in the mixing region lower, and the eddy turnover time will be longer. Thus, lower ozone concentrations were expected when slow quench flows were used. 
These considerations indicated that the quench velocity and the specific geometry of the quench-plasma interaction were expected play major roles in determining ozone production. This was found to be the case, as shown in Section 4.

\subsection{The ICP torch}

ICP torches $(9)$ as shown in Fig. 3 offer several advantages over DC systems: continuous operation due to the absence of electrode erosion; no process stream contamination by electrode material; no moving parts; and the ability to operate using a wider range of plasma-forming gases, including oxygen. The continuous operation capability and absence of electrodes in ICP torches are important advantages for industrial facilities.

ICP torches utilize electromagnetic induction, rather than the electric arc discharges used in conventional DC plasma systems, to couple electrical energy from a power supply into a toroidal discharge. The toroidal discharge in ICP systems acts as a short-circuited, single turn secondary winding of a transformer, the primary winding being a coil within the torch body. The RF energy is dissipated through ohmic heating of the plasma-forming gas, which reaches sufficiently high temperatures $(\sim 10,000 \mathrm{~K} \mathrm{or} \sim 1 \mathrm{eV})$ to achieve a high degree of ionization. The discharge can be initiated in several ways: (i) by reducing the pressure to $\sim 10-30 \mathrm{kPa}$, such that spontaneous breakdown occurs; (ii) by inserting an electrically conducting load, such as a graphite rod, into the torch to provide a localized source of ionization through induction heating; or (iii) applying a high voltage Tesla coil to the central probe of the torch to generate a spark which then ignites the plasma. The latter method was used in this case since the system was operated nominally at atmospheric pressure and with a sealed reactor.

ICP torches can be operated using a wide range of plasma-forming gases: argon, nitrogen, hydrogen, air and even pure oxygen, and at power levels up to $\sim 1 \mathrm{MW}$. Their energy efficiency is of the order of $15-40 \%$, lower than that of DC systems, but this is continually being improved through developments such as the use of solid-state power supplies, and by improved torch designs which either reduce radiative losses from the plasma to the cooling water(10) or which increase coil to plasma coupling-efficiency by eliminating the inner quartz tube $(11,12)$ commonly used in older designs.

The ozone synthesis experiments were carried out using a Tekna model Pl-35 ICP torch mounted on a water-cooled PERC ${ }^{\text {TM }}$ (Plasma Energy Recycle and Conversion) reactor chamber similar to that described by Smith, et al.(13) A schematic of the reactor, torch and FTIR spectrometer (described below) is shown in Fig. 4. The torch had an internal diameter of $35 \mathrm{~mm}$, and a 4 turn 
coil cast into the ceramic body. This torch had provisions for injecting three different gas flows: the central flow, the sheath flow, and the probe flow. The central flow provided the main plasma-forming gas, which was argon in these experiments. The sheath flow surrounded the central flow and the probe flow was introduced through a small stainless steel probe located on the torch axis. Both the sheath and probe flows were oxygen. Torch power was supplied from a Lepel vacuum tube, tuned-grid, $\mathrm{RF}$ generator via a $150 \mathrm{~mm}$ diameter coaxial copper transmission line and L-C matching network, or tank circuit. The torch-tank-RF generator combination was tuned for operation at a nominal frequency of $2.5 \mathrm{MHz}$, and optimized for maximum power coupling using an argon/oxygen mixture as the plasma-forming gas. RF power inputs of up to $25 \mathrm{kVA}$ were available, and the typical torch operating power was $\sim 11$ kVA.

\subsection{Reactor System Description}

The modular reactor is shown in Fig. 4. It consisted of 4 double-walled spool pieces, each $143 \mathrm{~mm}$ in length with an internal diameter of $152 \mathrm{~mm}$, with Viton ${ }^{\circledR}$ gasket seals between the section flanges. The top two sections of the reactor, located immediately beneath the torch, each incorporated four $44 \mathrm{~mm}$ internal diameter, flanged, side-arms, located $90^{\circ}$ apart, fitted with standard Conflat ${ }^{\circledR}$ vacuum flange seals, for use as instrumentation, view, or quench gas injection ports. The reactor was designed to provide a gas residence time of approximately $2 \mathrm{~s}$ at typical plasma gas flow rates. The reactor walls were water cooled to $\sim 10 \mathrm{C}$ during operation.

In the initial experiments, system pressure was controlled using three air-driven venturi pumps, or eductors, connected to the outlet of the reactor. Flow rate was controlled by varying the flow of compressed air supplied to the eductors. In later experiments at high quench gas flow rates, the eductor system was disconnected, since the quench gas flow greatly exceeded the pumping capacity of the eductor system, which led to high reactor pressures. In this case the chamber was exhausted directly to atmosphere through a 25 $\mathrm{mm}$ diameter hose. Reactor pressure was monitored using a simple water manometer connected directly to the reactor.

The plasma jet emerging from the ICP torch was quenched by a stream of room-temperature oxygen gas (not shown in Fig. 4). As discussed in Section 2 , ozone production was expected to be sensitive to the quench geometry and flow rate, so several different quench nozzles and orientations were used and the results compared. In each case, the quench system was operated under choked, or critical, flow conditions such that the flow rate was directly proportional to the supply pressure only. This was accomplished using 
critical orifices in the supply line or, for the smaller diameter nozzles, operating the nozzle under choked flow conditions so that it acted as a critical orifice. The top section of the reactor and the different quench nozzles used are shown schematically in Fig. 5. The different nozzles used and their orientations were:

A. A Spraying Systems, Inc. 'FullJet 1/8GA SS-8W' wide angle stainless steel conical nozzle located approximately $110 \mathrm{~mm}$ below the torch nozzle exit and directed into the torch throat. This nozzle had an orifice diameter of $2.38 \mathrm{~mm}$ and produced a $120^{\circ}-125^{\circ}$ divergent, full cone, gas stream. \#56 or \#47 critical orifices were used to control the gas flow rates.

B. A $2 \mathrm{~mm}$ internal diameter (ID) cylindrical nozzle on a $4.5 \mathrm{~mm}$ ID stainless steel tube directed across the plasma jet at the level of the first flange below the torch.

C. As described for quench arrangement $\mathrm{B}$, but with the $2 \mathrm{~mm}$ diameter nozzle removed so that the quench flow came directly from the $4.5 \mathrm{~mm}$ inner diameter stainless steel tube. A \#56 critical orifice was used to control the gas flow rate.

D. A $16 \mathrm{~mm}$ diameter port aimed directly across the plasma jet at a level slightly above the first flange below the torch.

E. A stainless steel tube with an oval crimped end of dimensions $1.8 \mathrm{~mm} \times 5$ $\mathrm{mm}$ (equivalent circular diameter $=3.2 \mathrm{~mm}$ ) aimed up at the torch at $\sim 45^{\circ}$ from the first flange below the torch. A \#56 critical orifice was used to determine flow rate from supply pressure. This nozzle could be rotated about the tube passing through the flange to allow the dependence of ozone production on angle to be studied.

F. A 'lazy-S' stainless steel tube originating at the first flange below the torch and bent to give a horizontal quench flow across the torch jet immediately below the torch exit opening. A $1.1 \mathrm{~mm}$ diameter nozzle was used on the end of this tube.

G. As described for quench arrangement $F$ but with a $2.2 \mathrm{~mm}$ diameter nozzle. The tube passing through the flange could also be rotated to enable angular dependence studies to be carried out. 
$\mathrm{H}$. As described for quench arrangement $\mathrm{F}$, but operated without a nozzle (ie. an open tube of $4.5 \mathrm{~mm}$ ID) and with a \#56 critical orifice.

\subsection{Ozone Concentration Measurements}

\subsubsection{FTIR Spectroscopy Diagnostics}

FTIR spectroscopy(14) of the plasma region was used to measure the ozone concentration since ozone is easily observed in the mid-infrared region of the spectrum (700-4000 $\mathrm{cm}^{-1}$ ) and because quantitative measurements are possible.

Absolute concentrations of molecular species can be deduced from measured absorbances of molecular vibrational bands and the gas temperature can be deduced from the relative absorbances of rotational lines in a vibrational band. This temperature is referred to as the rotational temperature and is usually equivalent to the bulk gas temperature in plasmas near atmospheric pressure. FTIR spectroscopy is not often performed in a plasma environment, although some studies have been made on low density processing plasmas such as those used in semiconductor manufacturing $(15,16)$. This is believed to be the first application of FTIR spectroscopy to a thermal plasma at atmospheric pressure. The primary difficulty in applying FTIR spectroscopy to the plasma is noise on the spectrum due to background infrared radiation from the plasma. This increases the detection limit for a given species over the value that would be obtained if the plasma were not present. Nevertheless, useful measurements of both species concentrations and the rotational temperature can be made. Note also that species concentrations and the rotational temperature measured by FTIR spectroscopy are averaged along the spectrometer line-of-sight through the plasma and surrounding region of the reactor chamber.

A schematic of the experimental arrangement used for FTIR spectroscopy of the ICP torch plasma is shown in Fig. 4. The infrared beam from a Mattson Infinity 60AR FTIR spectrometer operating in external beam mode was passed through the reactor via potassium bromide $(\mathrm{KBr})$ windows and observed on the opposite side by a liquid nitrogen-cooled, narrow-band mercury cadmium telluride (MCT) detector. $\mathrm{KBr}$ was selected as the material for both the FTIR spectrometer beamsplitter and the windows on the reactor because of its good transmission in the mid-infrared region. The vertical position of the beam path was positioned to pass through the plasma jet as close as possible to the ICP torch nozzle exit. This allowed the ozone concentration and gas temperature to be measured in the region of the plasma where mixing with the oxygen quench gas occurred. This was also 
where ozone formation was expected to take place. Data from the MCT detector was acquired and processed by the PC used to control the spectrometer.

The beam paths between the spectrometer and the reactor and the detector were enclosed by plastic tubes purged with dry nitrogen to minimize contributions to the spectra from water vapor and carbon dioxide in the room air. The FTIR spectrometer was not purged, but internal desiccators were used to remove water vapor. The external beam window of the FTIR spectrometer was placed as close as possible $(\sim 0.2 \mathrm{~m})$ to the reactor to minimize vignetting of the infrared beam. The MCT detector was placed at a much greater distance from the chamber $(\sim 1 \mathrm{~m})$ to reduce the relative contribution of infrared radiation from the plasma to the signal(16). This technique is effective because the intensity of the plasma emission decreases nominally as the square of the distance from the plasma, while the intensity of the infrared beam decreases more slowly. The signal-to-noise ratio of the measurements was therefore improved by increasing the separation between the detector and the plasma. The collimated infrared beam was focused onto the small area of the MCT detector by an off-axis ellipsoidal mirror.

For both the ozone concentration and gas temperature measurements, the plasma spectra were taken as single-beam spectra. These were ratioed with background single-beam spectra taken without the plasma to obtain absorbance spectra. The absorbance is defined as $A=-\log _{10}\left(I^{\prime} / I_{0}\right)$, where $I$ is the intensity of the transmitted infrared beam in the presence of the plasma and $\mathrm{I}_{0}$ is the background intensity. Background spectra were taken with argon gas flowing through the plasma torch in order to displace room air from the reactor.

\subsubsection{Ozone Spectrum and Measurement of Ozone Concentration}

Ozone concentrations were deduced from the absorbance of the ozone antisymmetric stretching band at $1042 \mathrm{~cm}^{-1}$. This band was chosen because it is the strongest ozone vibrational band and because it is free from interference from water bands. Fig. 6 shows an ozone spectrum of the 1042 $\mathrm{cm}^{-1}$ band taken at $2 \mathrm{~cm}^{-1}$ spectral resolution. 512 scans were summed and the total scan time was approximately 2 minutes. Spectra taken at spectral resolution of $0.125 \mathrm{~cm}^{-1}$ yielded the same absorbance values, but did not reveal additional detail in the shape of the band. This was expected because the spacing of the ozone rotational lines is less than their pressure broadening at atmospheric pressure. The lower resolution data had the advantage of a higher signal-to-noise ratio for the same total scan time. 
The ozone concentration was related to the measured band absorbance using Beer's law(14):

$$
A=\varepsilon 1 c
$$

where $\mathrm{A}$ is the absorbance, $\varepsilon$ is the ozone absorptivity, 1 is the path length through the sample, and $\mathrm{c}$ is the ozone concentration. The absorbance integrated over the entire band, or integrated band absorbance, was used for the ozone concentration measurements. Baseline subtraction was performed prior to integration. The absorptivity is a constant characteristic of a particular species and band. The absorptivity of the $1042 \mathrm{~cm}^{-1}$ ozone band was taken from measurements by McCaa and Shaw (17). The path length was assumed to be the distance between the $\mathrm{KBr}$ windows, $0.28 \mathrm{~m}$, since this was the length of the region where ozone was present. Analysis of the spectrum shown in Fig. 6 yielded an ozone concentration of $220 \mathrm{ppm}$ referred to atmospheric pressure, i. e., $2.20 \times 10^{-4}$ atm ozone partial pressure.

The peak-to-peak noise on the spectrum at $1042 \mathrm{~cm}^{-1}$ was measured at the baseline torch operating condition with no oxygen quench gas flow, a condition where no ozone was observed. This corresponded to a minimum detectable ozone level of $5 \mathrm{ppm}$. This is a conservative value because the peak-to-peak noise level was used. The noise on the spectrum varied somewhat with the torch operating parameters and quench gas flow rate, but this value for the detection limit may be taken as typical.

\section{Experimental Results}

\subsection{ICP Torch Operating parameters}

The plasma jet was ignited using argon as sheath, central, and probe gases and allowed to stabilize. Once stable operation was achieved, the sheath and probe gases were gradually changed from argon to oxygen. Air flow through the eductors was then adjusted to maintain a reactor pressure of $\sim-50 \mathrm{~mm}$ of water column in cases where active pumping was used.

A series of experiments was carried out to investigate the dependence of ozone production on quench gas flow rate, quench gas flow velocity, and quench geometry. Torch operating parameters, such as plasma input power, plasma gas composition, and probe and sheath gas flow rates, were also varied to determine their influence on ozone concentration and to map out the operating envelope within which significant concentrations of ozone were produced. After some initial studies, a standard set of torch operating parameters was used for most of the experiments. These 'baseline' parameters were: $\mathrm{RF}$ power $\approx 11 \mathrm{kVA}$ (plate voltage $\approx 8 \mathrm{kV} \times$ plate current $\approx 1.4$ 
A), oxygen sheath gas flow rate $=50 \mathrm{slm}$, argon central gas flow rate $=20 \mathrm{slm}$, and oxygen probe gas flow rate $=2.5 \mathrm{slm}$. Unless otherwise stated, the experiments described below were performed with the torch operating at the baseline condition.

\subsection{Ozone Concentration Dependence on Guench Flow Rate and Velocity}

Initial results were obtained with the torch operating at the baseline parameters and with quench nozzle A (see Fig. 5). This quench arrangement was chosen because injection of the quench gas in a direction counter to the plasma jet was expected to result in a high relative velocity between the torch plasma jet and the quench flow, and thus lead to rapid mixing and high ozone concentrations.

Fig. 7 shows the dependence of ozone concentration on quench gas flow rate for two experiments using this quench nozzle, one with active pumping by the eductor system and the other without active pumping. These results demonstrated several basic characteristics of ozone production by this technique: 1) an appreciable flow of quench gas was required for significant ozone production; 2) the ozone concentration at a given quench flow rate was reproducible; 3) the ozone concentration increased with increasing quench gas flow rate; and 4) the ozone concentration approached saturation at high quench gas flow rates.

As discussed in Appendix 1, the background gas temperature at the higher quench gas flow rates was low: 350-400 K, whereas it was measured to be $\sim 1000 \mathrm{~K}$ with no quench gas flow. (Note that, while the simulation discussed in Section 2 predicted a core temperature of $\sim 4000 \mathrm{~K}$, the FTIR spectroscopy measurements of the gas temperature discussed in Appendix 1 were line-ofsight averaged values and were therefore expected to be significantly lower than the predicted values. In addition, the simulation did not include the cooling effect of the quench gas flow.) The rate of thermal dissociation of ozone via reaction $\mathrm{R} 3$ is high at a temperature of $\sim 1000 \mathrm{~K}$, explaining why a quench flow was required to produce measurable ozone. The saturation of ozone concentration with increasing quench gas flow rate is an indication that a limit to increasing the efficiency of the quench gas mixing with the torch flow was being reached as the quench flow increased, not that the gas temperature was too high to prevent ozone loss by thermal dissociation, since the thermal dissociation rate was small at temperatures of 350-400 K.

Because a critical orifice was used to control the quench gas flow rate in this quench arrangement, the flow velocity at the quench orifice increased with increasing flow rate. Thus, the increase in ozone production with 
quench flow rate was probably due to more rapid mixing resulting from the higher quench velocity at the higher quench flow rates, as well as to the larger volume of quench gas injected per unit time.

The role of the diameter of the quench nozzle in determining ozone production is shown clearly in Fig. 8, which shows the ozone concentration for three quench nozzles with different diameters. These were quench nozzles B, C, and D shown in Fig. 5. At a given quench flow rate, much less ozone was produced by quench gas flowing through the large $16 \mathrm{~mm}$ diameter opening of quench nozzle $\mathrm{D}$ than by either of the other two quench arrangements, which had smaller diameters of $2 \mathrm{~mm}$ and $4.5 \mathrm{~mm}$ respectively. The larger diameter, and therefore lower quench flow velocity, of nozzle $\mathrm{D}$, led to slow, inefficient mixing of the quench gas with the plasma jet and therefore to low ozone concentrations. The ozone concentrations produced by quench nozzles $\mathrm{B}$ and $\mathrm{C}$ were similar in spite of their very different flow speeds. This may be because the smaller and faster quench from nozzle B entrained less atomic oxygen as it passed through the torch flow.

The ozone concentrations obtained with quench nozzle B and shown in Fig. 8 also demonstrate reproducibility at a given quench flow rate. The ozone concentration in this case increased rapidly with increasing quench flow rate and then rolled over at the highest quench flow rates. This behavior may indicate that most of the entrained oxygen atoms had reacted to form ozone and that the higher quench flow rates were beginning to dilute the ozone. The ozone production rate, which was proportional to the product of ozone concentration and quench flow rate, remained approximately constant with increasing quench flow rates. Lacking detailed local measurements it was not possible to quantitatively model this behavior.

Fig. 9 shows ozone concentrations for quench nozzles $F$ and $G$. The quench flow was across the plasma jet in both cases and the only differences were the nozzle diameters: $1.1 \mathrm{~mm}$ for nozzle F and $2.2 \mathrm{~mm}$ for nozzle G. Both nozzles were operated under choked flow conditions over the range of quench flow rates shown in Fig. 9, so the flow speed at the orifice was near the local speed of sound. Fig. 9 shows that more ozone was produced by the smaller nozzle than by the larger one at a given quench flow rate. At a given flow rate, the pressure in the smaller orifice must be higher and this is presumed to drive a larger amplitude of expansion/contraction oscillations in the downstream quench flow. This may have increased entrainment of torch gas into the quench flow, accounting for the higher ozone production. 


\subsection{Ozone Concentration Dependence on Quench Flow Geometry}

Comparison of the higher ozone concentrations produced by quench nozzle A shown in Fig. 7 with the lower values shown for nozzles B, C, D, F, and $\mathrm{G}$ in Figs. 8 and 9 implies that the detailed geometry of the plasma jet/quench jet interaction is important in determining ozone production. This is not surprising because changes in the geometry of this interaction could change the plasma jet/quench jet relative velocity, the quantity of atomic oxygen entrained by the quench jet, and the turbulence in the plasma jet/quench jet mixing region. In particular, the broader, fan-shaped quench jet produced by nozzle A interacted with a larger volume of the plasma jet than the quench jets produced by nozzles B, C, F, and G. Thus, although quench nozzle A produced a slower quench flow at a given flow rate than nozzles $\mathrm{B}, \mathrm{F}$, and $\mathrm{G}$, it may have produced more ozone because a larger fraction of the torch output interacted with the quench flow. Two additional sets of experiments were carried out to investigate the effect of changing the plasma jet/quench jet interaction in a systematic way.

The first set of experiments was performed using quench nozzle G. The tube passing through the flange was rotated to position the nozzle at different locations relative to the plasma jet. The effect of this rotation on the ozone concentration is shown in Fig. 10. The position denoted $0^{\circ}$ indicates that the nozzle was positioned to aim the quench jet through the nominal center of the plasma jet, as shown in Fig. 5. In this position, the intersection of the quench jet with the plasma was closest to the torch nozzle exit. Positive angles correspond to the tube being rotated clockwise when viewed facing the flange outside the reactor and negative angles indicate counterclockwise rotation. Note that when the tube was rotated away from $0^{\circ}$ the quench jet intercepted the plasma jet farther from the torch exit opening and farther from the torch axis. In this figure, and in Fig. 11, repeated angle settings for which the angle was changed to a different value following the first set of measurements and then reset to a nominally similar value for the second set of measurements are denoted by numbers in parentheses following the angle, i.e., the point labeled $+30^{\circ}(2)$ in Fig. 10 was obtained after the quench nozzle had been reset to an angle of $+30^{\circ}$ following the measurement at $-30^{\circ}$. The quench angle was also set to a value a few degrees smaller than $30^{\circ}$ for points labeled $<30^{\circ}$.

Several observations may be made from Fig. 10: 1) the ozone concentration was very sensitive to quench jet angle; 2) the highest ozone concentrations were produced with the nozzle positioned at $+30^{\circ}$, not at $0^{\circ} ; 3$ ) the plasma flow was not symmetric because the ozone concentrations obtained with the 
nozzle at $-30^{\circ}$ were lower than those at $+30^{\circ}$; 4) the dependence of ozone concentration on quench flow rate was different for different quench angles; and 5) it was not possible to reproduce the high ozone concentrations obtained at $+30^{\circ}$ in the later runs. According to the simulation of the plasma torch, the atomic oxygen was in a column with a diameter of $\sim 30 \mathrm{~mm}$. When the quench nozzle was rotated $\sim 30^{\circ}$ from the vertical, the quench jet only intercepted the edge of this high temperature core of the plasma jet. The maximum torch jet/quench flow intersection angle is expected to occur at angles between $0^{\circ}$ and $45^{\circ}$. The asymmetry in ozone concentration between $+30^{\circ}$ and $-30^{\circ}$ may be due to the swirl of the central gas flow in the torch, such that the plasma jet/quench jet relative velocity was lower for the $-30^{\circ}$ case than for the $+30^{\circ}$ case.

Similar experiments were carried out with quench nozzle E, with the tube passing through the flange rotated to vary the angle at which the quench intercepted the plasma jet. The results are plotted in Fig. 11 and the basic features are similar to those obtained for quench nozzle G in Fig. 10. In this case, however, the highest ozone concentrations were seen at $+45^{\circ}$, and lower values were observed at $+30^{\circ},+90^{\circ}$, and $-45^{\circ}$. A second attempt to reproduce the results at $+45^{\circ}$ was more successful than with nozzle $\mathrm{G}$, but a significant difference remained between the ozone concentrations at the highest quench flow rate.

Both of these experiments demonstrated that the position and direction of the quench nozzle also played important roles in determining the ozone concentration at a given quench flow rate. The variability of the ozone concentration in some cases indicated strong sensitivity to the precise location of the plasma jet/quench jet interaction.

Fig. 12 shows the ozone concentration produced with quench nozzles $G$ and $\mathrm{H}$, both oriented at an angle of $+30^{\circ}$. Nozzle $\mathrm{G}$ had a $2.2 \mathrm{~mm}$ ID orifice, while nozzle $\mathrm{H}$ had a $4.5 \mathrm{~mm}$ ID orifice. As shown in Fig. 12, nozzle $\mathrm{H}$ produced less ozone than nozzle $G$ at low quench flow rates, but the ozone concentrations were similar for the two nozzles at high quench flow rates. The flow from the larger nozzle was estimated to become sonic at a flow of $\sim 300 \mathrm{slm}$. As a result, the quench flow velocity was lower for the larger nozzle than the smaller one at all quench flow rates. It was shown earlier that with nozzles $\mathrm{B}$ and $\mathrm{C}$ the larger orifice produced more ozone, (Fig. 8.) In those configurations the quench gas was directed through the center of the torch column, whereas in Fig. 12 the quench flowed past the edge of the column. 


\subsection{Dependence of Ozone Concentration on Torch Operating Parameters}

The effect of varying the following ICP torch operating parameters on ozone concentration was also studied: $\mathrm{RF}$ power, probe gas flow rate, and sheath gas flow rate.

Fig. 13 shows the ozone concentration produced at three different torch $\mathrm{RF}$ power levels using quench nozzle $\mathrm{G}$ rotated to $+30^{\circ}$. The ozone concentration was strongly dependent on RF power, with the maximum at the intermediate RF power level, which corresponded to the baseline operating condition. This behavior may have been due to the low RF power being insufficient to thermally dissociate a large volume of oxygen, while at high power levels the torch enthalpy was so high that the quench gas did not sufficiently cool the entrained gas.

The effect of varying the sheath gas flow rate over a range compatible with stable torch operation on ozone concentration is shown in Fig. 14. The ozone concentration decreased slowly with increasing sheath gas flow rate, but the decrease was small, approximately $35 \%$ for a factor of two change in the sheath gas flow rate. This decrease was probably due to shrinkage of the hot core of the plasma resulting from cooling as the sheath gas flow rate was increased. The smaller interaction region would reduce entrainment of atomic oxygen into the quench flow.

The ozone concentration was found to be constant within $\sim 15 \%$ for probe gas flow rate variations from 0 to $7.5 \mathrm{slm}$ around the baseline value of 2.5 slm. It is likely that most of the atomic oxygen which became ozone was created at the inner boundary of the sheath gas flow. At the modest probe gas flow rates used here, the probe flow should not suppress dissociation in the hot core of the plasma.

\section{Summary of Results and Directions for Further Development}

Significant amounts of ozone, up to $250 \mathrm{ppm}$, were produced in these experiments, demonstrating the technical feasibility of ozone synthesis using a quenched ICP torch. Both the quench gas flow rate and velocity were found to be important in determining the ozone concentration for a given quench configuration. These observations confirmed the initial hypothesis that a high degree of mixing of the quench gas with the plasma flow in a short period of time is crucial for producing high ozone concentrations. The ozone concentration was also very sensitive to the position of the quench jet with respect to the plasma flow, indicating that the quench jet must be directed toward a region of high atomic oxygen concentration for efficient 
production of ozone. The ozone concentration was also sensitive to the torch $\mathrm{RF}$ power, with the highest concentrations being obtained at intermediate RF power levels, but the ozone concentration was relatively insensitive to the sheath and probe gas flow rates.

While significant, the ozone concentrations produced in these experiments were lower than the commercially-relevant level of $1 \%$ by over an order of magnitude. Quench nozzles with small diameter orifices produced the highest velocity quench jets, which produced ozone locally where the jets interacted with the plasma; however, these quench jets did not interact with a large enough fraction of the plasma jet for high overall efficiency in ozone production. Conversely, the quench configurations that produced larger diameter quench jets which interacted with larger portions of the plasma flow had low velocities which did not lead to efficient mixing of the quench gas and plasma flows, and thus had low local ozone production efficiency.

These observations indicate a path for further development of this ozone synthesis technique: an array of small diameter, high speed quench flows directed into the hot region of the plasma jet. The nozzles to produce these flows could be arranged in a semicircular array around the plasma (quench flows directed into each other would produce stagnation) and several such arrays of nozzles could be located at different levels below the torch exit nozzle to utilize the entire length of the plasma jet. It might also be possible to build an array of quench nozzles into the body of the torch. Such an arrangement would make effective use of the bulk of the plasma jet, and thus produce higher ozone concentrations than were obtained in the experiments reported here.

\section{Acknowledgements}

The authors would like to thank M. Goeckner of the Princeton Plasma Physics Laboratory (PPPL) for valuable guidance on FTIR spectroscopy and S. Larson of PPPL for making possible use of the FTIR spectrometer. The support of L. Meixler of PPPL is greatfully acknowledged. We would also like to thank A. Blutke of Thermal Conversion Corp. (formerly Plasma Technology, Inc.) and J. Vavruska of Equinox, Ltd. for useful discussions. Thanks are also due to Professor E. Grossmann and Mr. R. Guddeti of Drexel University for their help in performing the experiments. We would also like to thank Professor M. I. Boulos and Mr. R. Ye of the University of Sherbrooke for modeling of the torch plasma and Professor J. Jurewicz of Tekna Plasma Systems, Inc. for general help on torch operation. This work was carried out with support from U.S. Department of Energy Contract DE-AC02-76-CHO3073. 


\section{Appendix 1. Rotational Temperature Measurement}

The gas temperature could not be measured using the FTIR spectrum for ozone because its closely spaced rotational lines could not be resolved due to pressure broadening at atmospheric pressure. Instead, a small amount of carbon dioxide was introduced via the quench gas nozzle and the rotational spectrum of the antisymmetric stretching band at $2349 \mathrm{~cm}^{-1}$ was used to measure the rotational temperature.

Carbon dioxide is a linear, symmetric molecule (point group $\mathrm{D}_{\infty} \mathrm{h}$ ) and its rotational structure may therefore be treated using a formalism similar to that for diatomic molecules. The relative intensities of the rotational transitions in the $2349 \mathrm{~cm}^{-1}$ band observed in absorption are determined by the relative populations of the rotational levels in the ground state. At atmospheric pressure, the populations of the ground state rotational levels are described by an expression derived from the Boltzmann relation(18):

$$
N_{J^{\prime \prime}} / N_{O}=\left(2 J^{\prime \prime}+1\right) \exp \left[-h_{c} B^{\prime \prime} J^{\prime \prime}\left(J^{\prime \prime}+1\right) / k T\right]
$$

where $\mathrm{N}_{\mathrm{J}}$ ' is the population of the level with total angular momentum quantum number $\mathrm{J}^{\prime \prime}, \mathrm{B}^{\prime \prime}$ is the rotational constant of the ground state of the molecule, h is Planck's constant, c is the speed of light, $\mathrm{k}$ is Boltzmann's constant, and $\mathrm{T}$ is the temperature. The measured absorbance of a rotational line is proportional to the population of the lower level of the transition. Thus, the temperature can be deduced by fitting a straight line to a plot of $\ln \left[A /\left(2 J^{\prime \prime}+1\right)\right]$ versus $J^{\prime \prime}\left(J^{\prime \prime}+1\right)$; the temperature is inversely proportional to the slope, hcB"/kT.

An example of a measured carbon dioxide spectrum is shown in Fig. 15. This spectrum was obtained under the standard torch operating conditions with no oxygen quench gas. Quench nozzle A was used to introduce a small amount of carbon dioxide. The rotational lines were identified using the tables of Oberly, et al.(19) and interfering lines from combination bands and hot bands, as well as those from isotopes other than $12_{\mathrm{C}} 16_{\mathrm{O}_{2}}$, were

eliminated. This left only the rotational lines of the $12 \mathrm{C}^{16} \mathrm{O}_{2}$ fundamental vibrational band. Both the P- and R-branches of the $2349 \mathrm{~cm}^{-1}$ band were analyzed. Lines with $J^{\prime \prime}$ less than 32 for the P-branch and less than 38 for the R-branch were also excluded because their populations could be significantly influenced by contributions from room temperature carbon dioxide due to imperfect subtraction of the background spectra. 21 lines were used for the P-branch analysis and 16 lines were used for the R-branch analysis. 
Fig. 16 shows the fit to the P-branch plot; its slope yielded a temperature of $1275 \mathrm{~K}$ using the value of $\mathrm{B}^{\prime \prime}$ from Herzberg(20). A similarly good fit to the R-branch data was obtained, and its slope corresponded to a temperature of $829 \mathrm{~K}$. Ideally, the two values should be equal, but some difference is usually seen in measurements of this type. There was no reason to prefer one value over the other so the two were averaged to give a temperature of $1052 \pm 223 \mathrm{~K}$. This uncertainty is very conservative as it spans the range of the two measurements. This temperature is consistent with the observation that no ozone was measured in the absence of an oxygen quench gas flow, since any ozone produced would be rapidly destroyed at such a high temperature by the back reactions $\mathrm{R} 3$ and $\mathrm{R} 4$. Note that this temperature was a line-of-sight average and was therefore much lower than the predicted value of $\sim 4000 \mathrm{~K}$ for the hottest region of the plasma. It was not possible to measure the rotational temperature in the presence of a significant oxygen quench gas flow, as the available apparatus did not allow the carbon dioxide to be mixed with the quench gas at the high pressure required for the quench gas flow.

The bulk gas temperature in the reactor with non-zero oxygen quench gas flow was estimated using a capillary thermometer inserted through the reactor wall. These measurements indicated temperatures ranging from 450 $\mathrm{K}$ to $350 \mathrm{~K}$ as the quench gas flow rate increased from $189 \mathrm{slm}$ to $566 \mathrm{slm}$ for the data plotted in Fig. 7 without active pumping by the eductor system. As expected, these values were lower than the rotational temperature measured with no quench gas flow and indicated a decrease in temperature with increasing quench gas flow. Thus, the higher quench gas flow rates resulted in sufficiently low gas temperatures to prevent ozone destruction by the temperature-sensitive back reaction R3. 


\section{References}

1. Horváth, M., Bilitzky, L., and Hüttner, J., Ozone, Elsevier, Amsterdam, 1985.

2. Eliasson, B., Hirth, M., and Kogelschatz, U., J. Phys. D, 20, 1421 (1987).

3. Kogelschatz, U. and Eliasson, B., "Ozone Generation and Applications," in Handbook of Electrostatic Processes, Marcel Dekker, New York, pp. 581-605, 1995.

4. Eliasson, B., Hirth, M., and Kogelschatz, "Basic Data for Modeling of Electrical Discharges in Gases: Oxygen," Technical Report KLR 86-11 C, ASEA Brown Boveri, 1986.

5. Mallard, W.G., Westley, F., Herron, J.T., Hampson, R.F., and Frizzell, D.H., NIST Chemical Kinetics Database: Version 6.0, National Institute of Standards and Technology, Gaithersburg, MD, 1994.

6. Boulos, M.I., Private Communication, 1997.

7. Rahamane, M., Soucy, G. and Boulos, M.I., Plasma Chem. and Plasma Proc., 16, 169S (1996).

8. Dowling, D.R., "Mixing in Gas-Phase Turbulent Jets," in Encyclopedia of Fluid Mechanics, Supplement 2, Gulf Publishing, Houston, TX, pp. 125, Houston, 1993.

9. Reed, T.B., J. Appl. Phys., 32, 821, (1961).

10. Tuszewski, M., "Efficiency of Inductively Coupled Plasmas for Environmental Recycling," Los Alamos National Laboratory, NM, CRADA Report, February, 1994.

11. Boulos, M.I., "Induction Plasma Processing for Material Synthesis and Waste Treatment," Proc. Workshop on Industrial Applications of Plasma Chemistry, 12th Int'l. Symp. on Plasma Chem. (ISPC-12), IUPAC, Minneapolis, MN, August 25-26, Vol. B Thermal Plasma Applications, pp. 89-95, 1995. 
12. Jurewicz, J. and Boulos, M.I., "High Energy Density Induction Plasma System for Materials Processing," Proc. 5 th Nat'1. Thermal Spray Conf. (NTSC '93), ASM Int'1., Anaheim, CA, pp. 89-95, 1993.

13. Smith, R.W., et al., "Induction-Coupled Plasma Energy Recycle and Conversion (PERC ${ }^{\text {TM}}$ ) of Military Waste Streams," Proc. Workshop on Industrial Applications of Plasma Chemistry, 12th Int'1. Symp. on Plasma Chem. (ISPC-12), IUPAC, Minneapolis, MN, August 25-26, Vol. B Thermal Plasma Applications, pp. 1057, 1995.

14. Griffiths, P.R., and de Haseth, J.A., Fourier Transform Infrared Spectrometry, John Wiley \& Sons, New York, 1986.

15. Cleland, T.A., and Hess, D.W., J. Appl. Phys., 64, 1068 (1988).

16. Goeckner, M.J., et al., J. Vac. Sci. Technol. A, 12, 3120 (1994).

17. McCaa, D.J., and Shaw, J. H., J. Molecular Spectroscopy, 25, 374 (1968).

18. Hollas, J.M., Modern Spectroscopy, Second Ed., John Wiley \& Sons, New York, 1992.

19. Oberly, R., et al., J. Molecular Spectroscopy, 25, 138 (1968).

20. Herzberg, G., Molecular Spectra and Molecular Structure, Vol. II, Infrared and Raman Spectra of Polyatomic Molecules, D. Van Nostrand Co., Princeton, NJ, 1956. 


\section{Figure Captions}

Fig. 1: $\left[\mathrm{O}_{3}\right] /\left[\mathrm{O}+\mathrm{O}_{3}\right]$ as a function of temperature for a range of values of $\left[\mathrm{O}+\mathrm{O}_{3}\right] /\left[\mathrm{O}_{2}\right]$.

Fig. 2: Dependence of $\left[\mathrm{O}+\mathrm{O}_{3}\right]$ destruction time scale, $\tau_{\mathrm{des}}$, on temperature for a range of values of $\left[\mathrm{O}+\mathrm{O}_{3}\right] /\left[\mathrm{O}_{2}\right]$.

Fig. 3: Schematic of an RF induction-coupled plasma (ICP) torch.

Fig. 4: Schematic of ozone production experiment showing ICP torch,reactor chamber, and FTIR spectrometer.

Fig. 5a: Quench nozzle A.

Fig. 5b: Quench nozzle B (used cap with $2 \mathrm{~mm}$ diameter orifice) and quench nozzle C (without cap; $4.5 \mathrm{~mm}$ ID tube acting as orifice). Quench D utilized the $16 \mathrm{~mm}$ diameter port.

Fig. 5c: Quench nozzle E.

Fig. 5d: Quench nozzle F (used cap with $1.1 \mathrm{~mm}$ diameter orifice); quench nozzle G (used cap with $2.2 \mathrm{~mm}$ diameter orifice); quench $\mathrm{H}$ (without cap; $3.2 \mathrm{~mm}$ inner diameter tube acting as orifice).

Fig. 6: FTIR spectrum of ozone antisymmetric stretching band at 1042 $\mathrm{cm}^{-1}$. An ozone concentration of $220 \mathrm{ppm}$ was deduced fromthis measurement.

Fig. 7: Dependence of ozone concentration on oxygen quench gas flow ratefor quench nozzle A operated with and without active pumping of the reactor.

Fig. 8: Dependence of ozone concentration on oxygen quench gas flow rate for quench nozzles B, C, and D.

Fig. 9: Dependence of ozone concentration on oxygen quench gas flow rate for quench nozzles $\mathrm{F}$ and $\mathrm{G}$.

Fig. 10: Effect of varying angle of quench nozzle G on ozone concentration.

Fig. 11: Effect of varying angle of quench nozzle $\mathrm{E}$ on ozone concentration. 
Fig. 12: Comparison of ozone concentrations produced by quench nozzles $\mathrm{G}$ and $\mathrm{H}$ rotated to an angle of $+30^{\circ}$.

Fig. 13: Dependence of ozone concentration on torch power for quench nozzle $\mathrm{G}$ rotated to an angle of $+30^{\circ}$.

Fig. 14: Dependence of ozone concentration on torch sheath gas flow rate for quench nozzle $\mathrm{G}$ rotated to an angle of $+30^{\circ}$.

Fig. 15: FTIR spectrum of carbon dioxide antisymmetric stretching band at $2349 \mathrm{~cm}^{-1}$.

Fig. 16: Fit to carbon dioxide P-branch spectrum used to measure rotational temperature. 


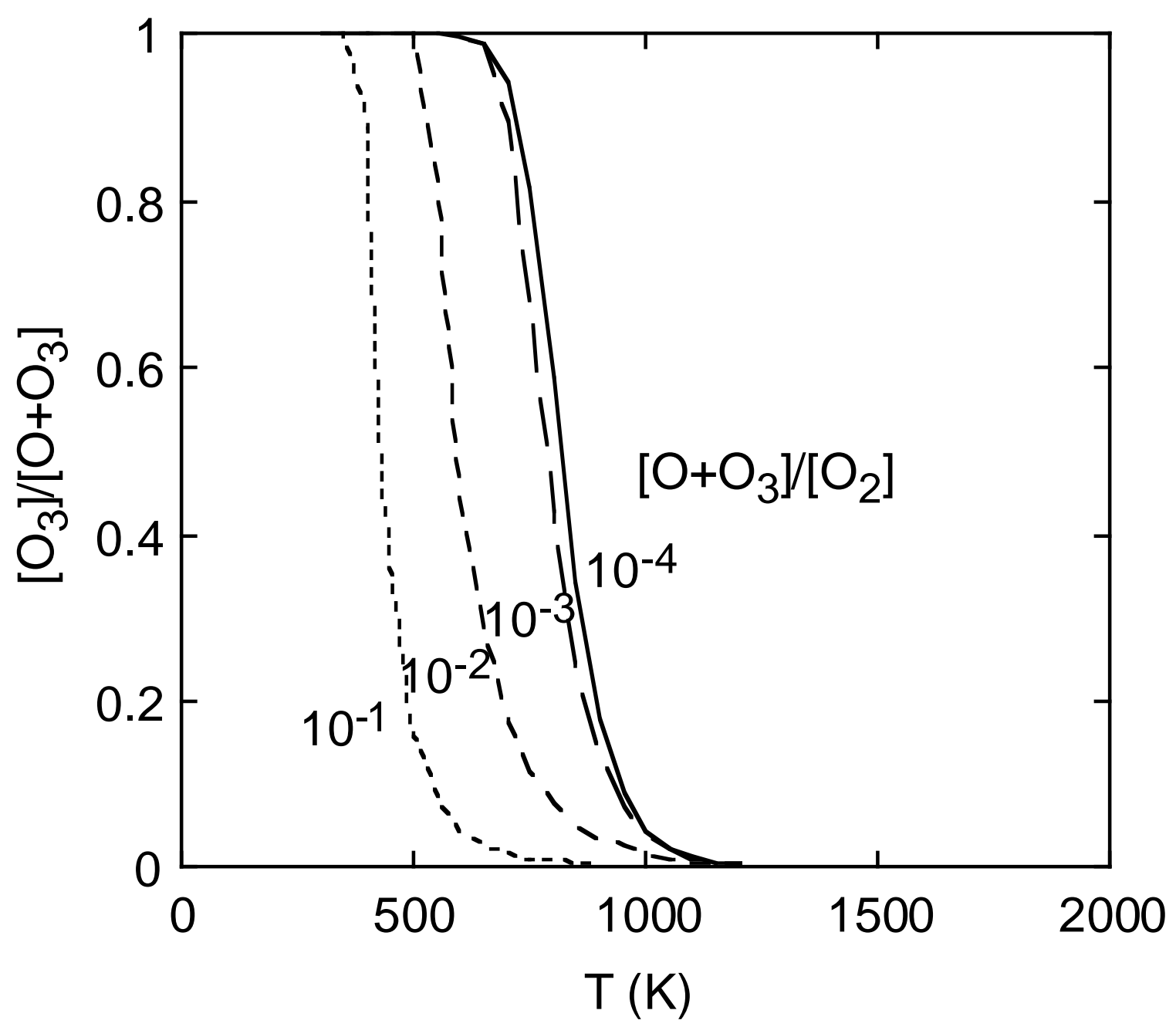

PPPL/3281/Fig. 1: $\left[\mathrm{O}_{3}\right] /\left[\mathrm{O}+\mathrm{O}_{3}\right]$ as a function of temperature for a range of values of $\left[\mathrm{O}+\mathrm{O}_{3}\right] /\left[\mathrm{O}_{2}\right]$. 


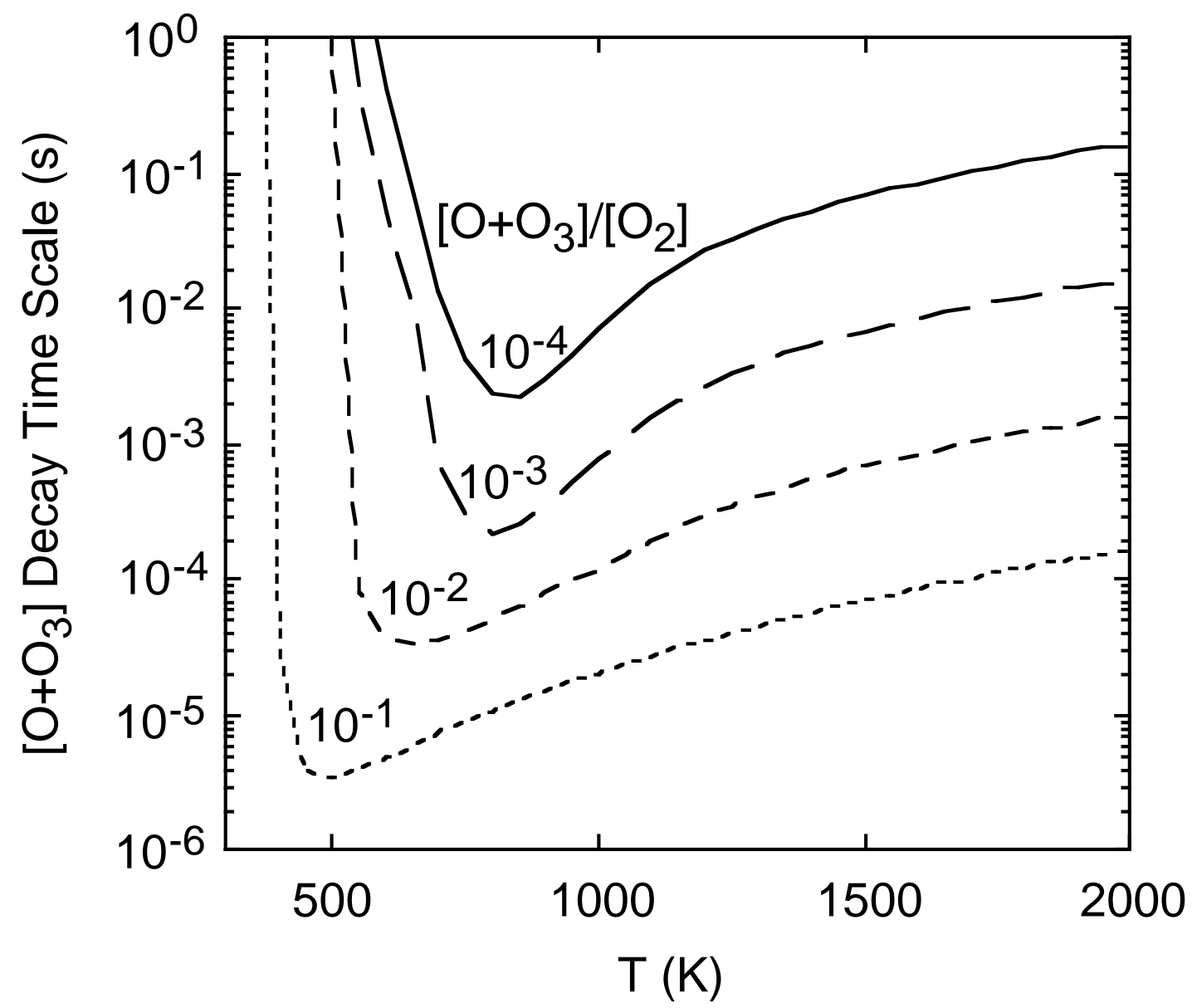

PPPL-3281/Fig. 2: Dependence of $\left[\mathrm{O}+\mathrm{O}_{3}\right]$ destruction time scale, $\tau_{\text {des }}$, on temperature for a range of values of $[\mathrm{O}+$ $\left.\mathrm{O}_{3}\right] /\left[\mathrm{O}_{2}\right]$. 


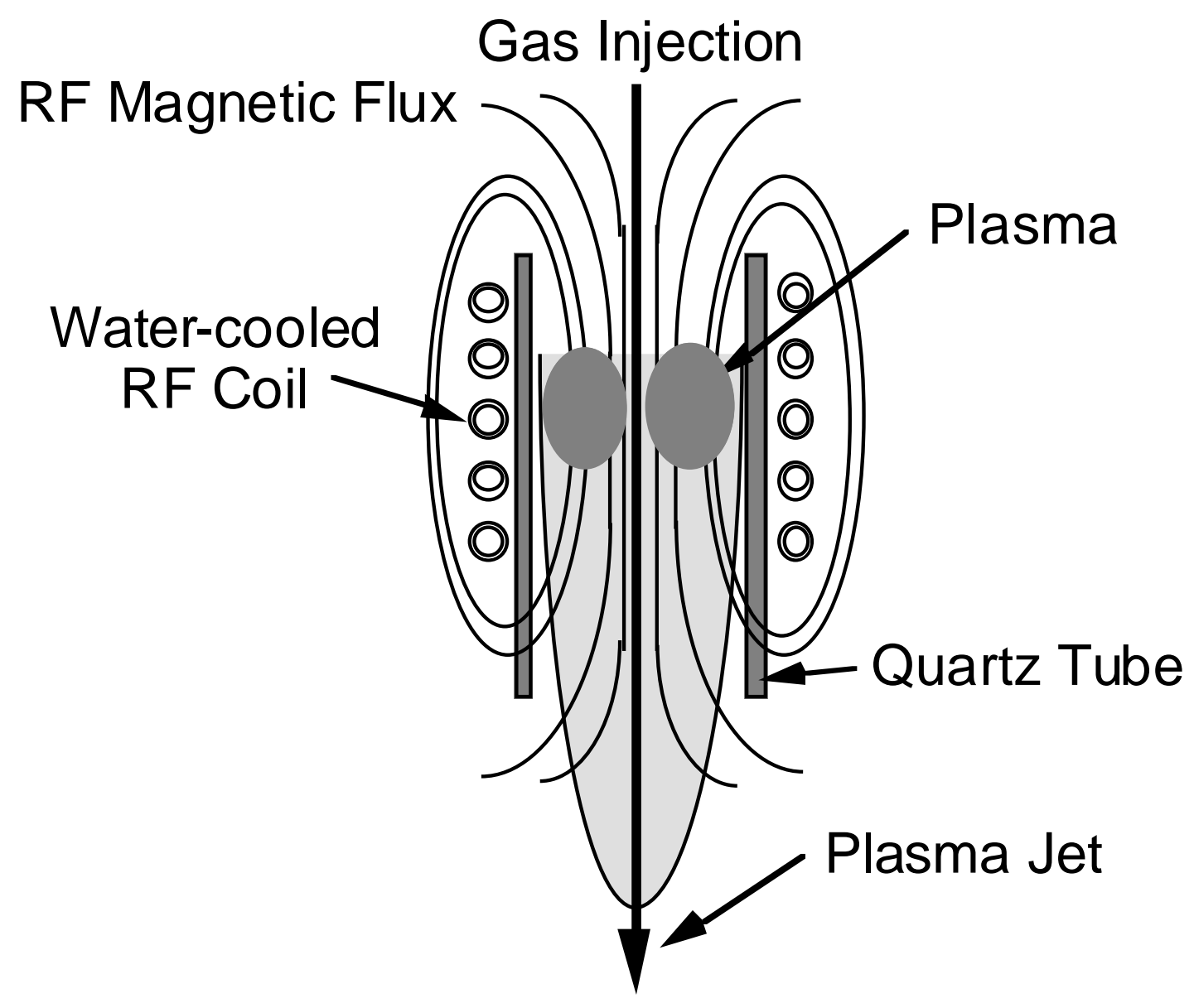

PPPL-3281/Fig. 3: Schematic of an RF inductioncoupled plasma (ICP) torch. 


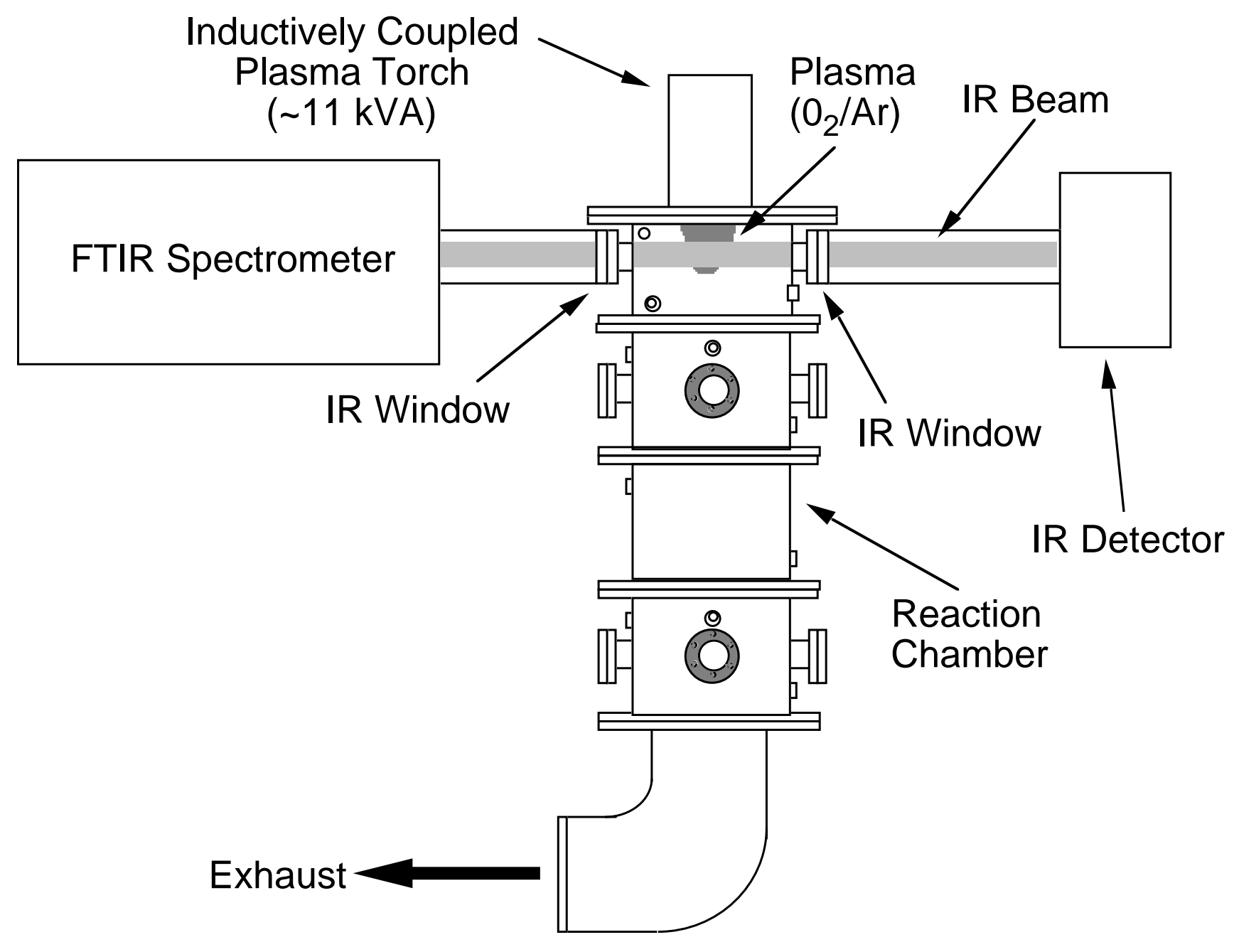

PPPL-3281/Fig. 4: Schematic of ozone production experiment showing ICP torch, reactor chamber, and FTIR spectrometer. 


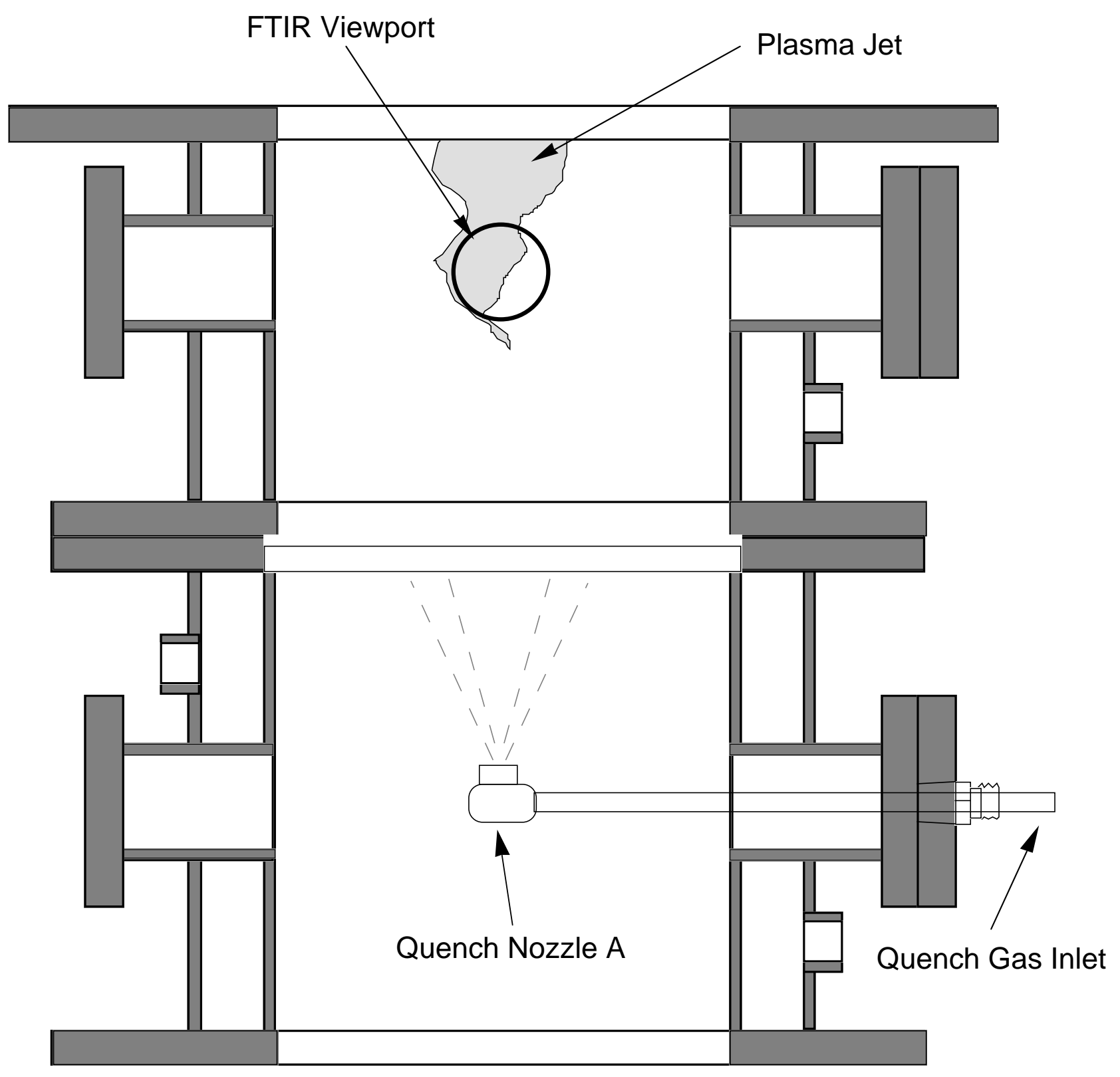

PPPL-3281/Fig. 5a: Quench nozzle A. 


\section{Gas Inlet for Quench D}

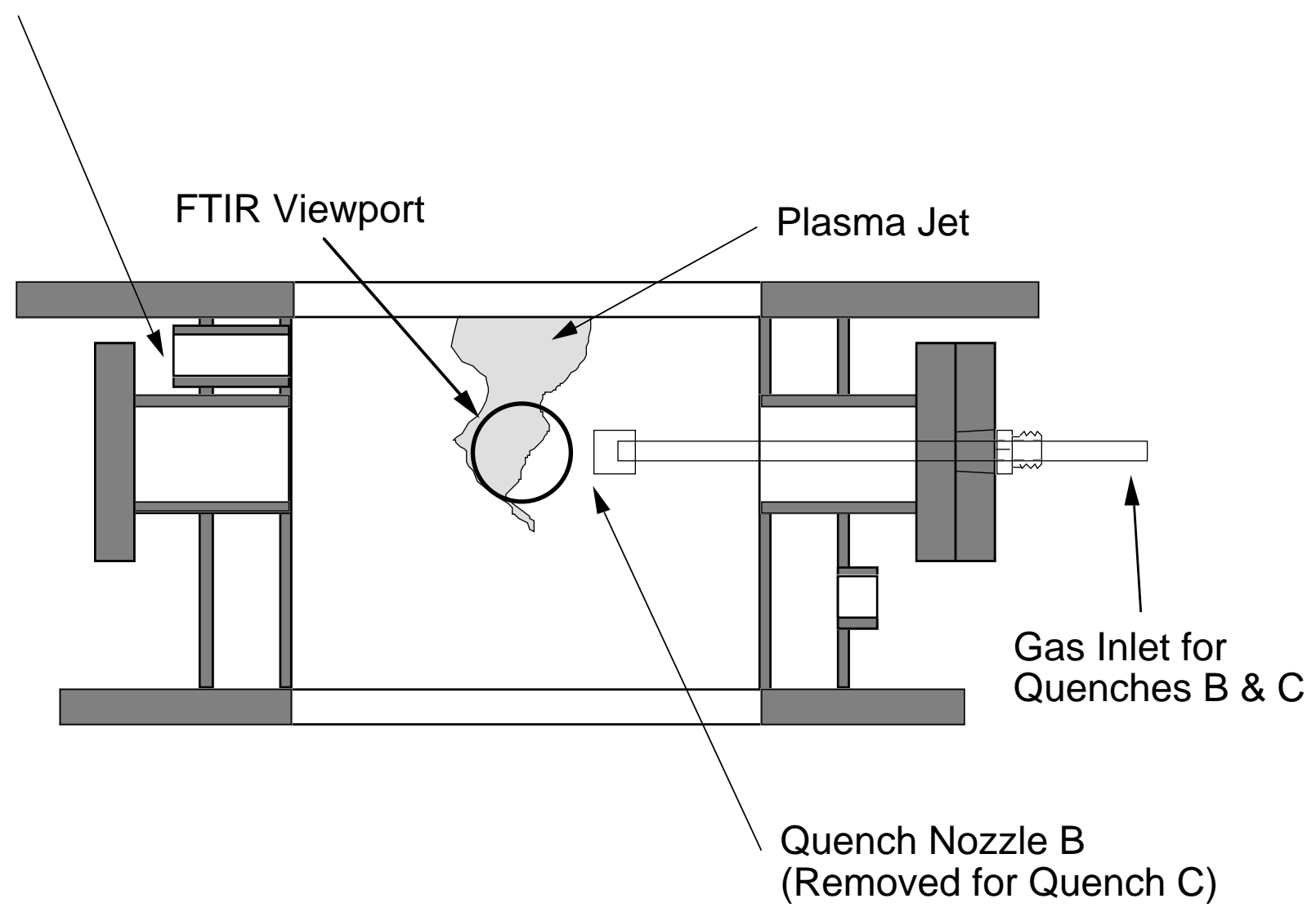

PPPL-3281/Fig. 5b: Quench nozzle B (used cap with $2 \mathrm{~mm}$ diameter orifice) and quench nozzle C (without cap; $4.5 \mathrm{~mm}$ ID tube acting as orifice). Quench D utilized the $16 \mathrm{~mm}$ diameter port. 


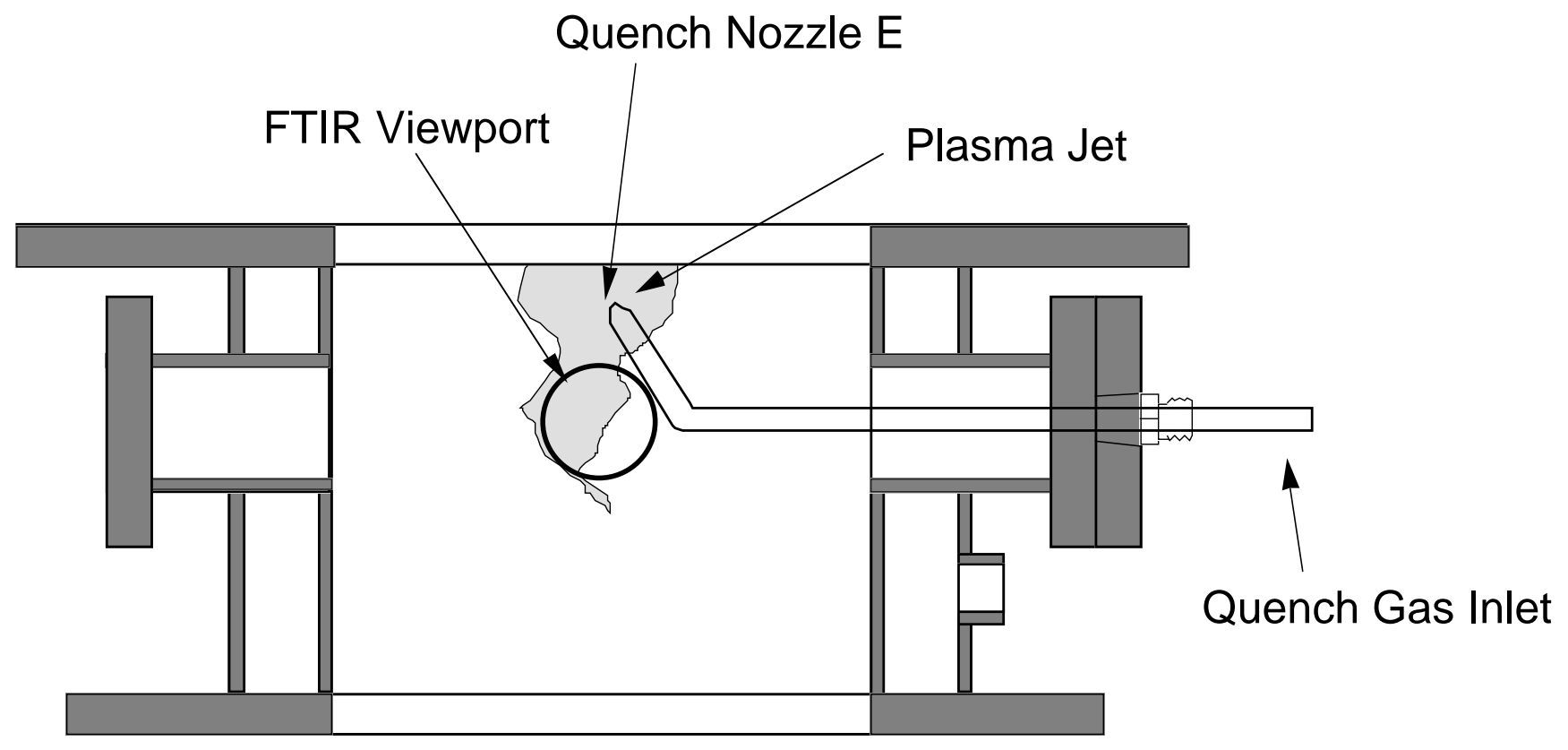

PPPL-3281/Fig. 5c: Quench nozzle E. 


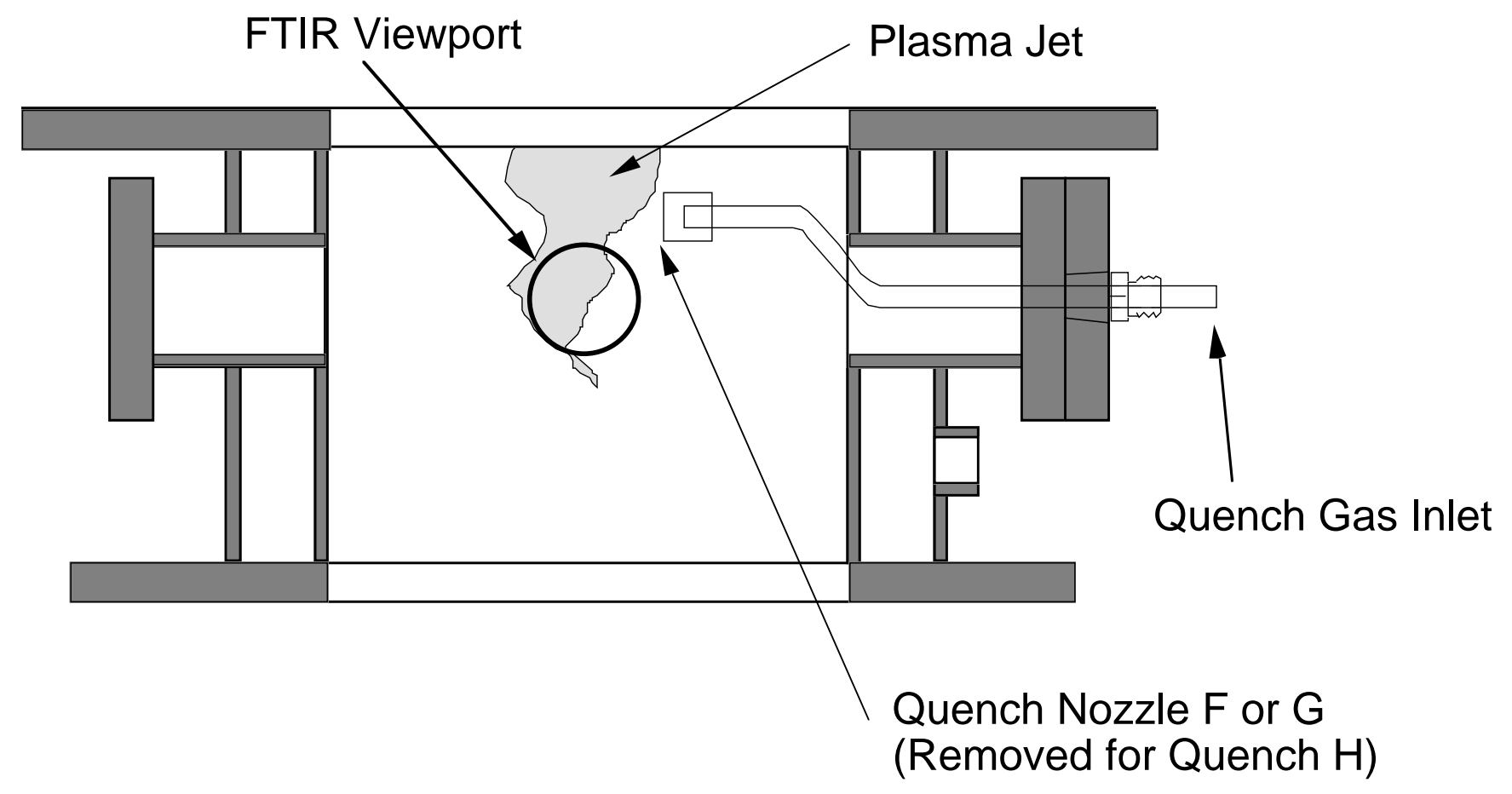

PPPL-3281/Fig. 5d: Quench nozzle F (used cap with $1.1 \mathrm{~mm}$ diameter orifice); quench nozzle $\mathrm{G}$ (used cap with $2.2 \mathrm{~mm}$ diameter orifice); quench $\mathrm{H}$ (without cap; $3.2 \mathrm{~mm}$ inner diameter tube acting as orifice). 


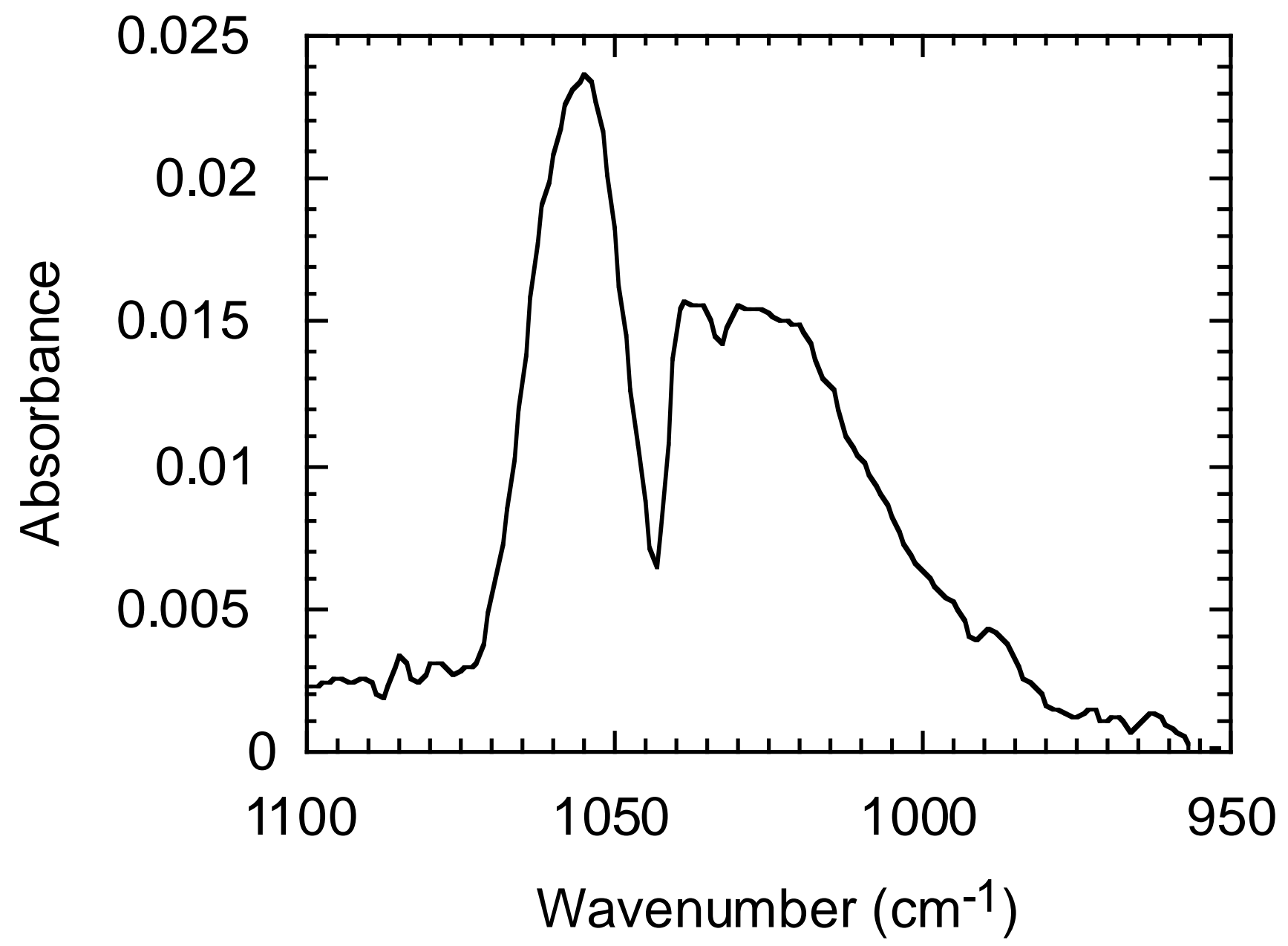

PPPL-3281/Fig. 6: FTIR spectrum of ozone antisymmetric stretching band at $1042 \mathrm{~cm}^{-1}$. An ozone concentration of $220 \mathrm{ppm}$ was deduced fromthis measurement. 


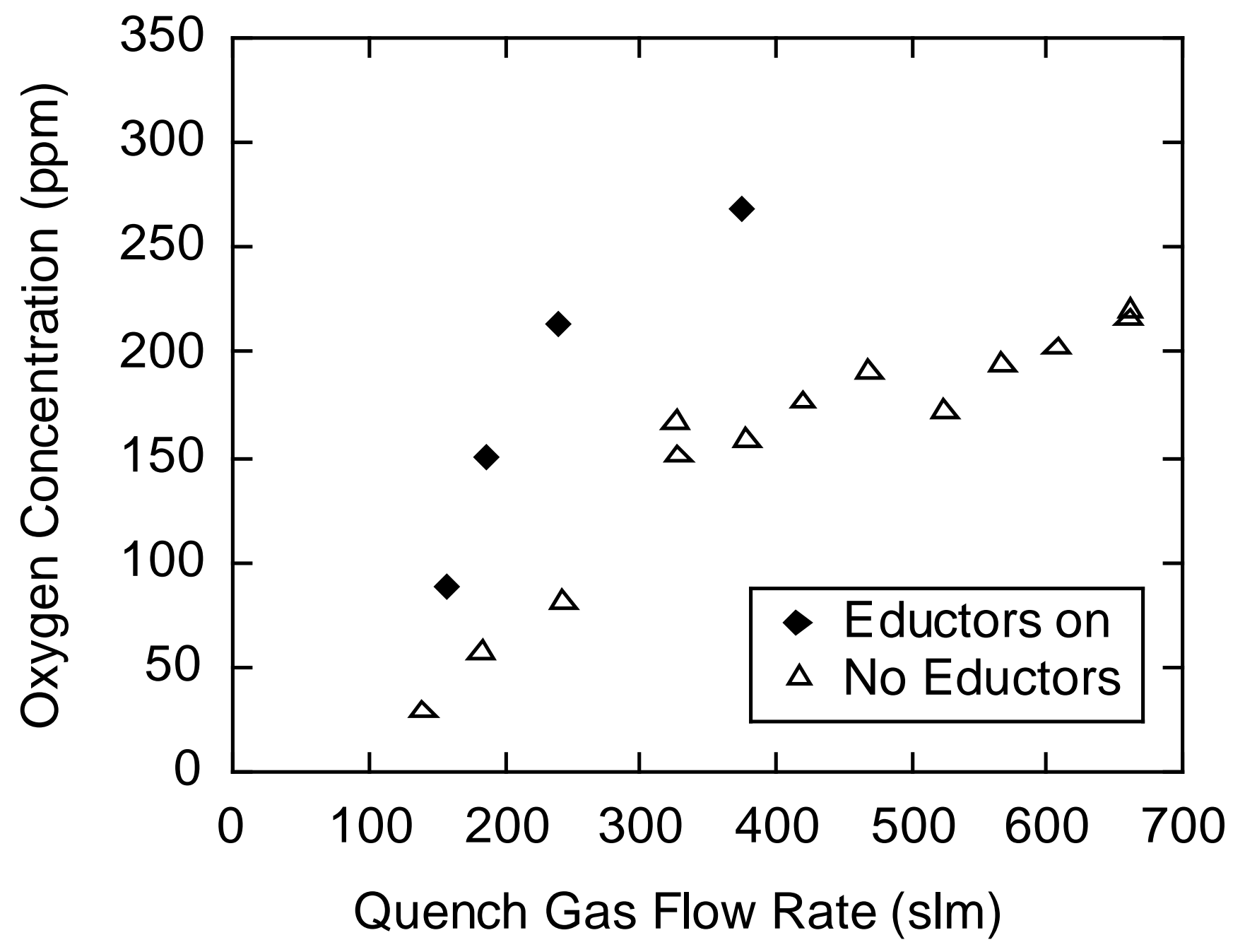

PPPL-3281/Fig. 7: Dependence of ozone concentration on oxygen quench gas flow ratefor quench nozzle $A$ operated with and without active pumping of the reactor. 


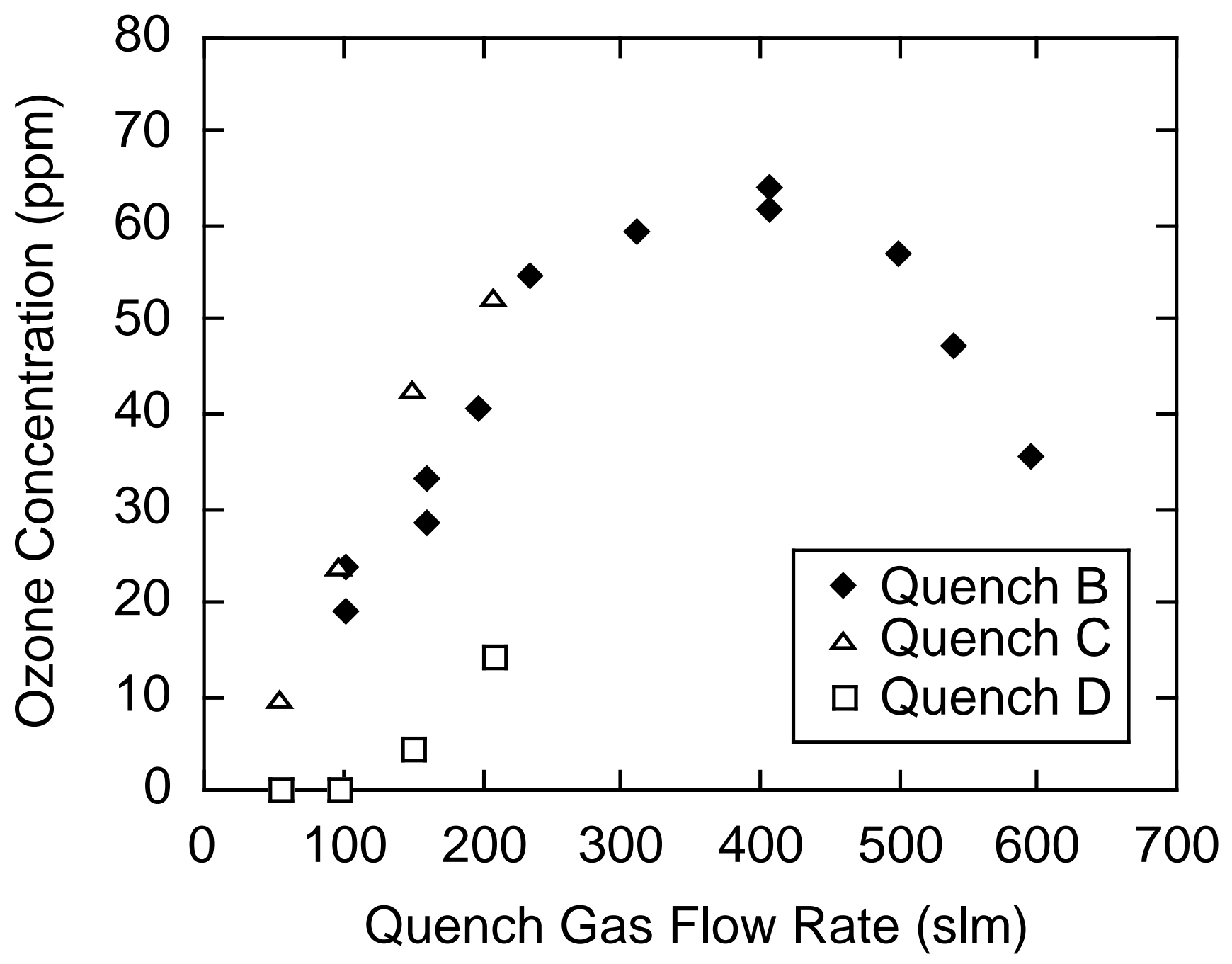

PPPL-3281/Fig. 8: Dependence of ozone concentration on oxygen quench gas flow rate for quench nozzles $B$, $\mathrm{C}$, and $\mathrm{D}$. 


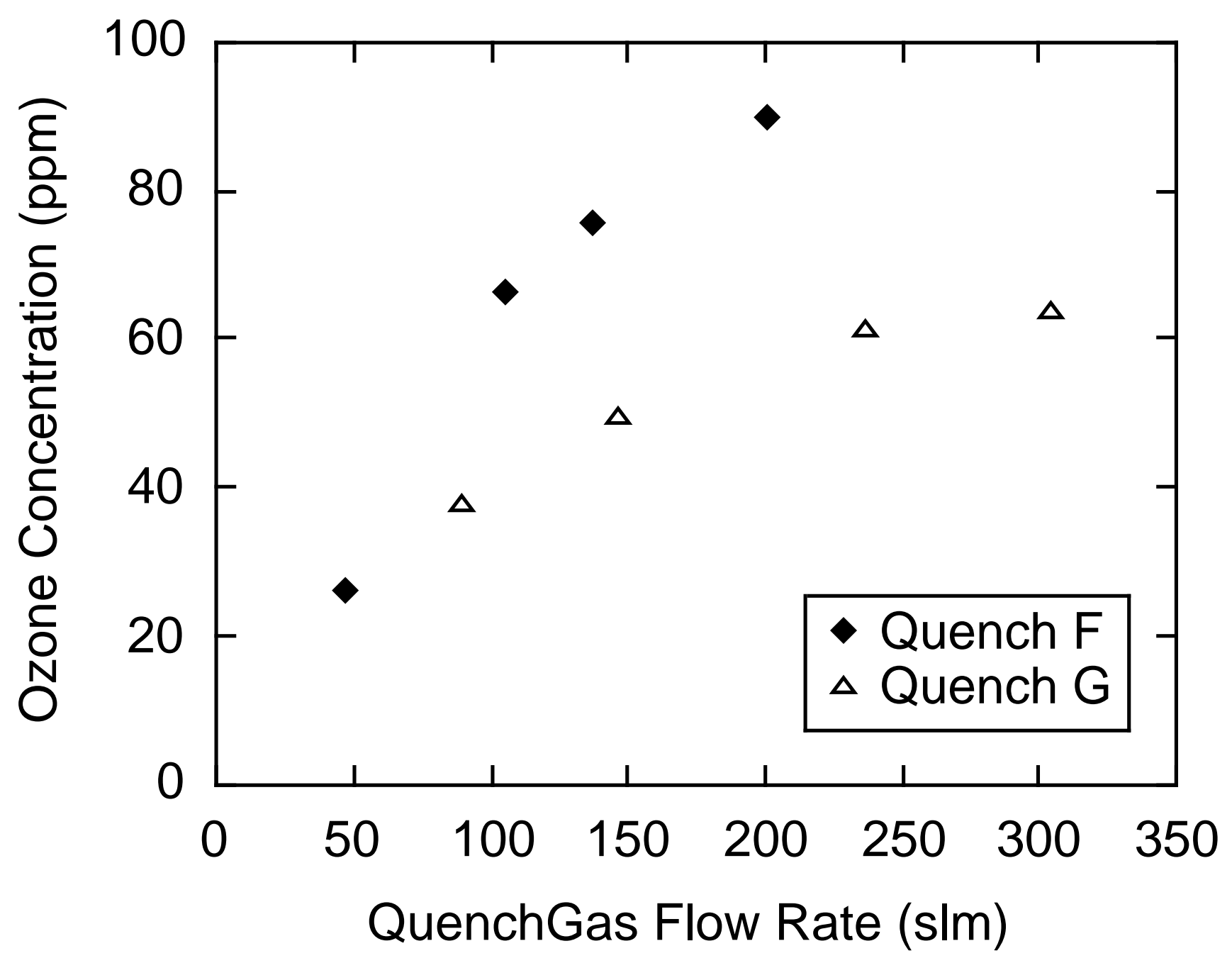

PPPL-3281/Fig. 9: Dependence of ozone concentration on oxygen quench gas flow rate for quench nozzles $F$ and $G$. 


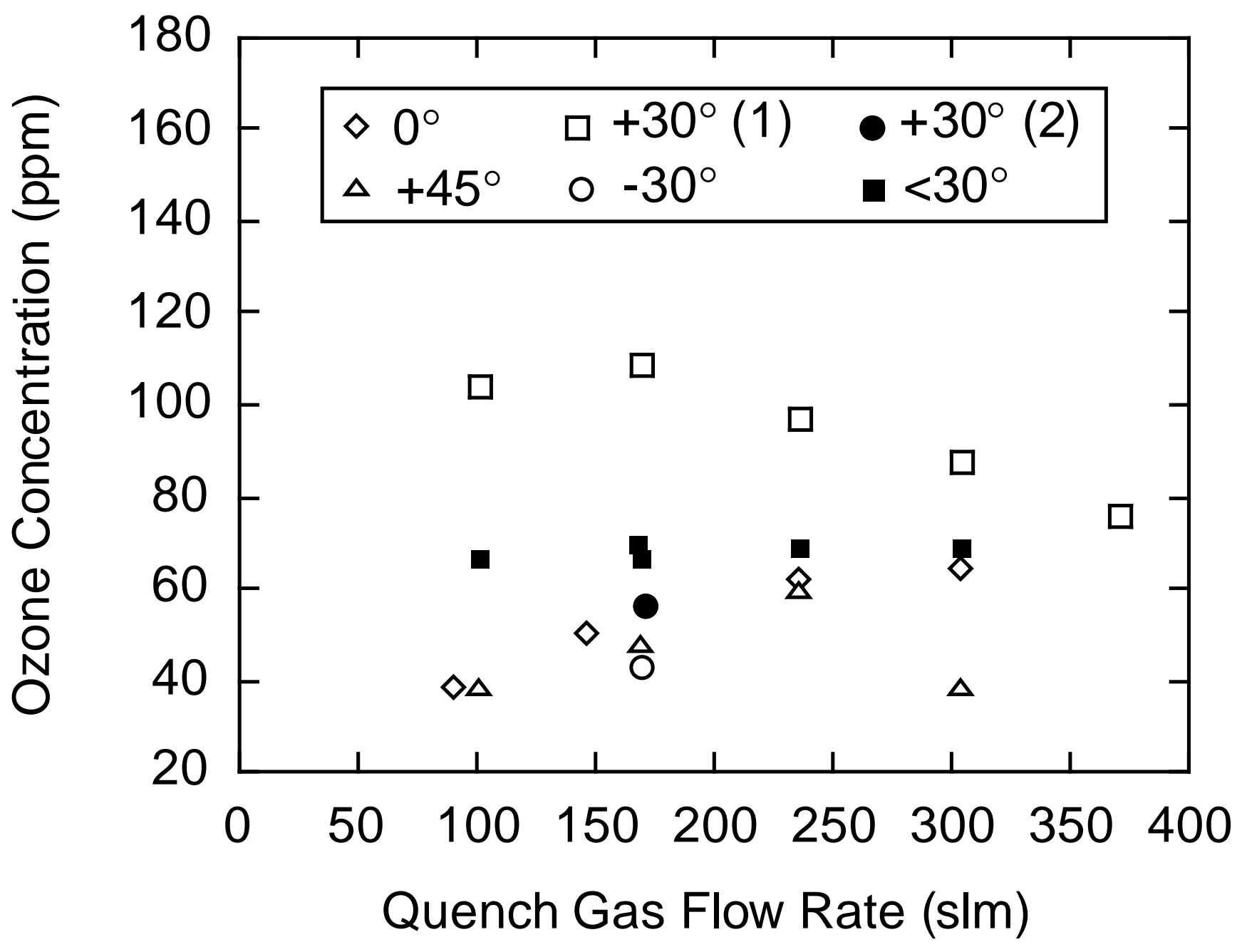

PPPL-3281/Fig. 10: Effect of varying angle of quench nozzle $G$ on ozone concentration. 


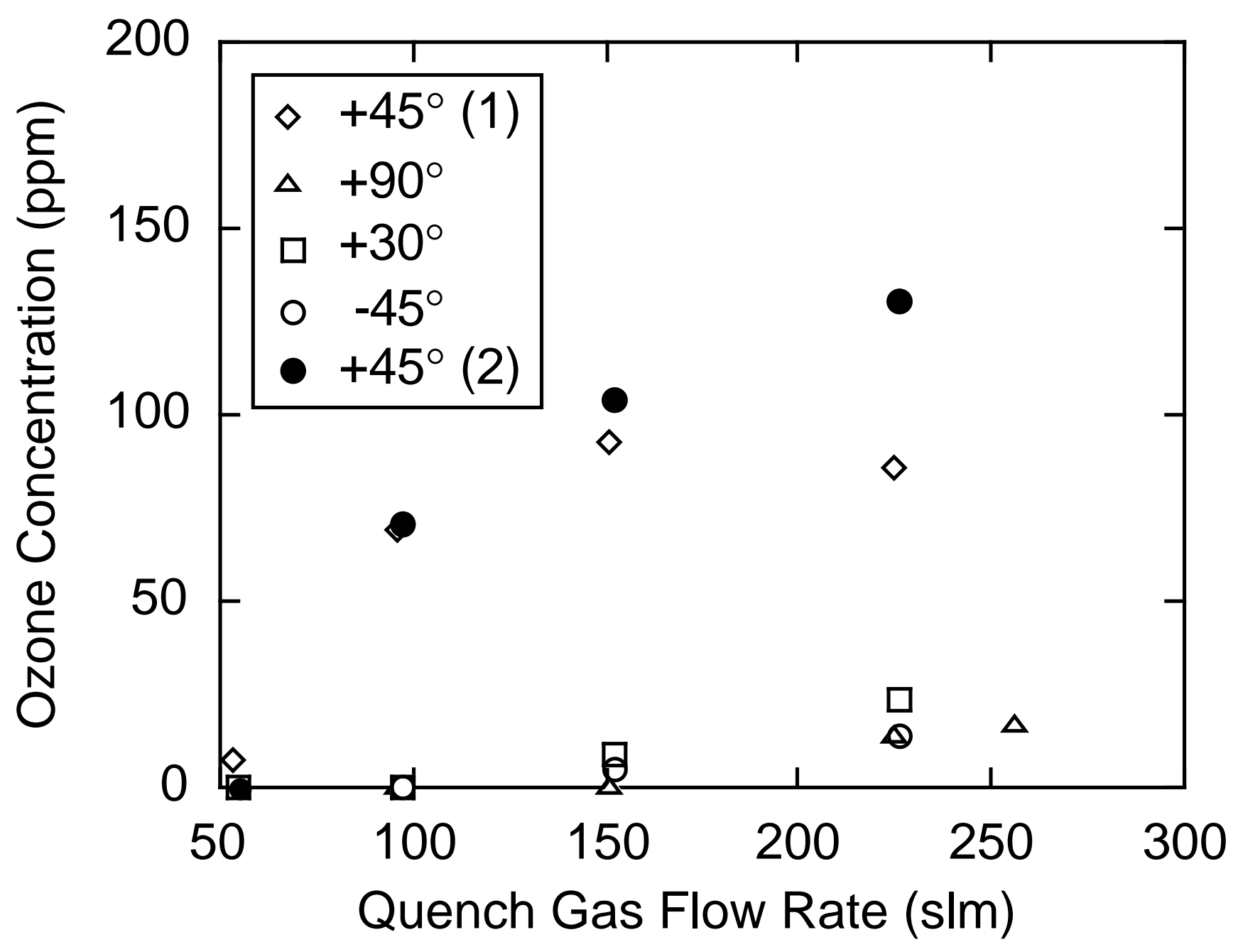

PPPL-3281/Fig. 11: Effect of varying angle of quench nozzle E on ozone concentration. 


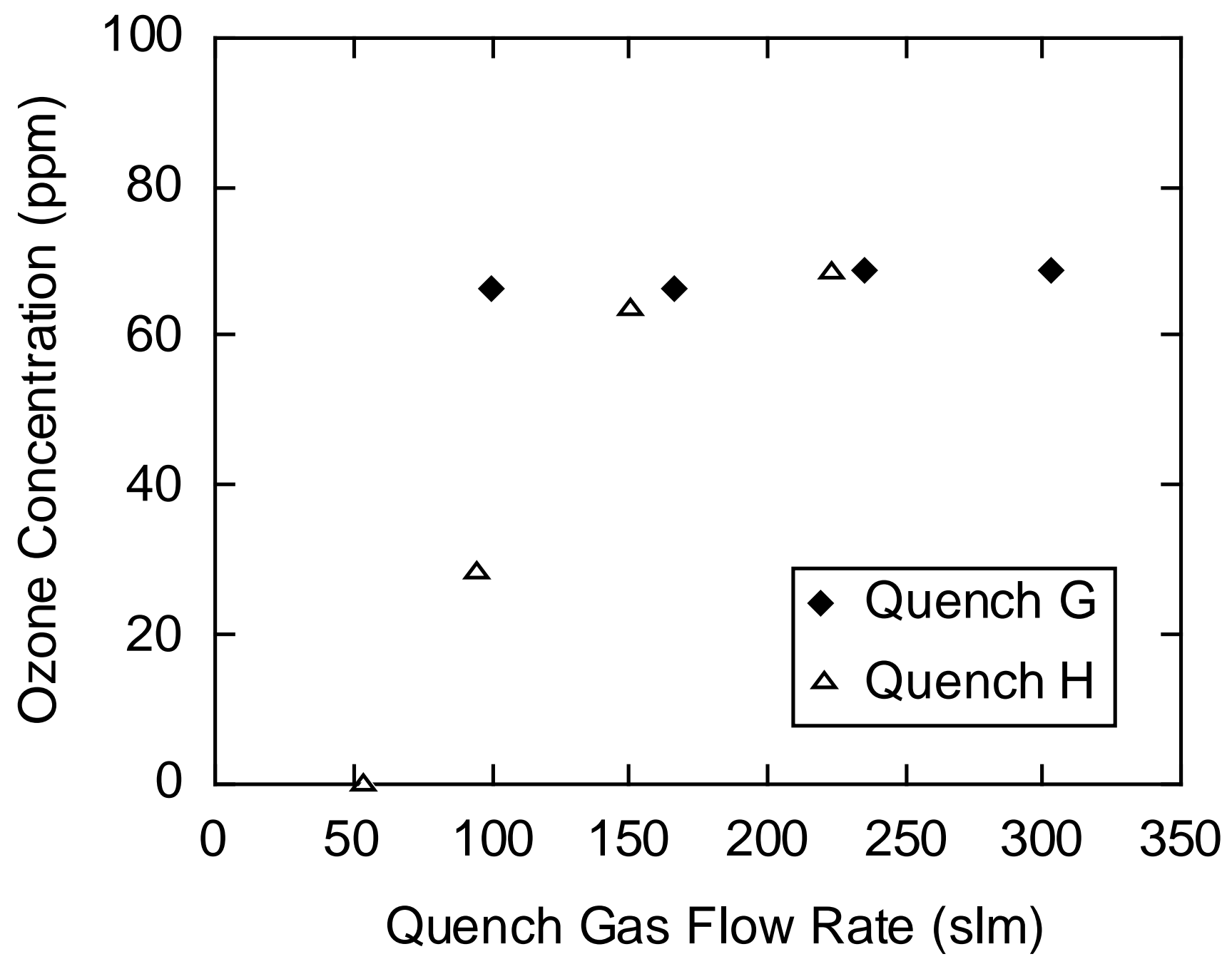

PPPL-3281/Fig. 12: Comparison of ozone concentrations produced by quench nozzles $\mathrm{G}$ and $\mathrm{H}$ rotated to an angle of $+30^{\circ}$. 


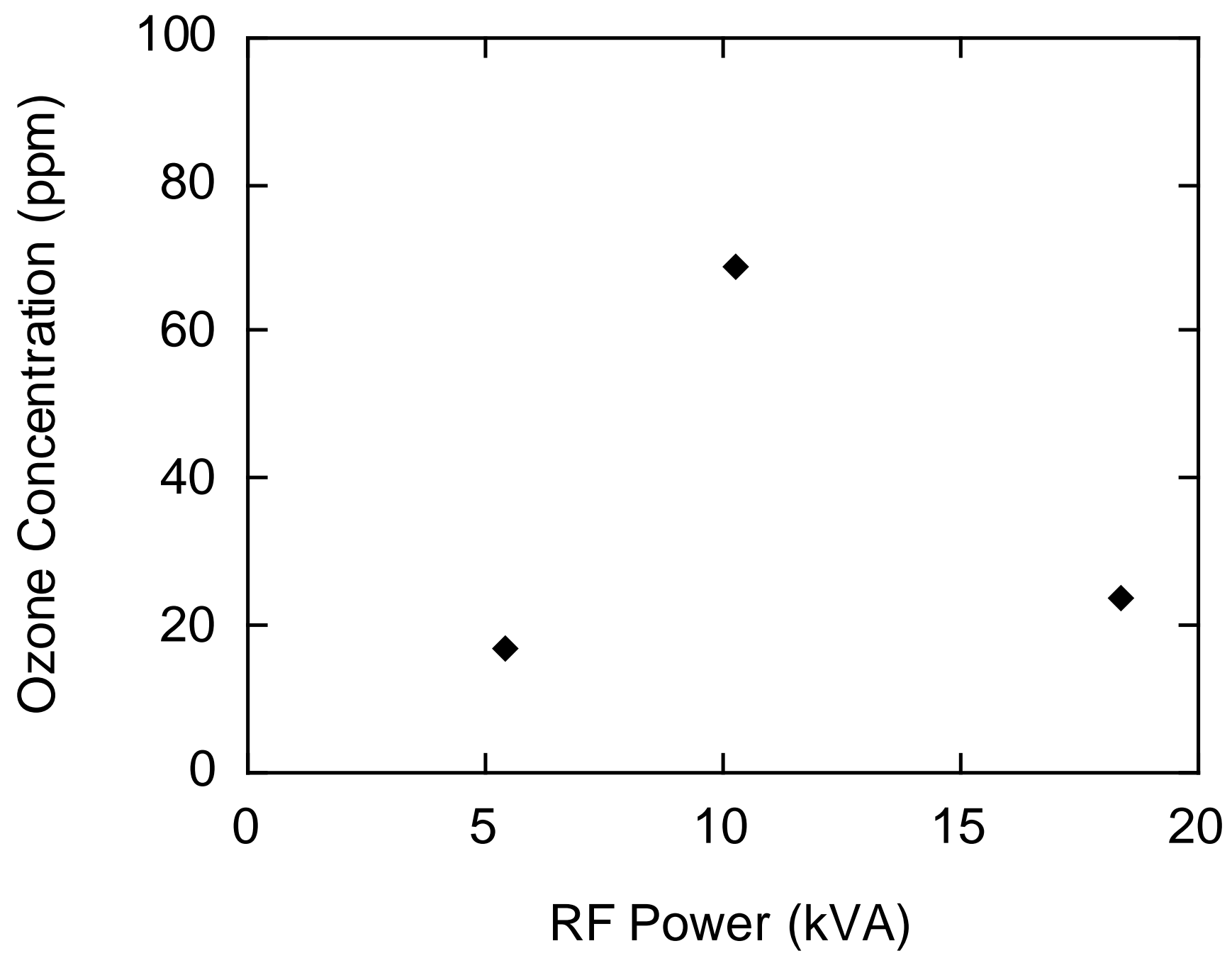

PPPL-3281/Fig. 13: Dependence of ozone concentration on torch power for quench nozzle $G$ rotated to an angle of $+30^{\circ}$. 


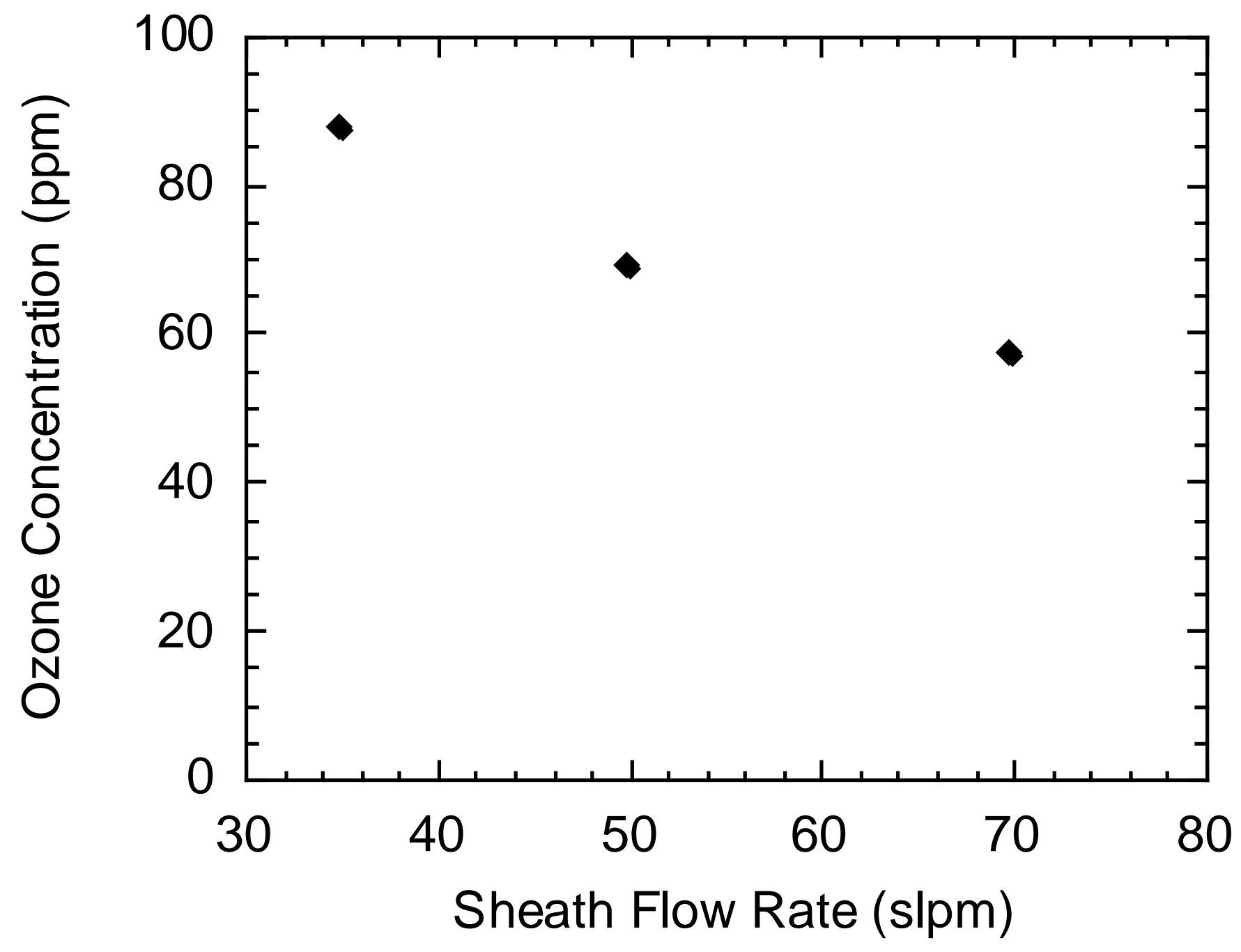

PPPL-3281/Fig. 14: Dependence of ozone concentration on torch sheath gas flow rate for quench nozzle $G$ rotated to an angle of $+30^{\circ}$. 


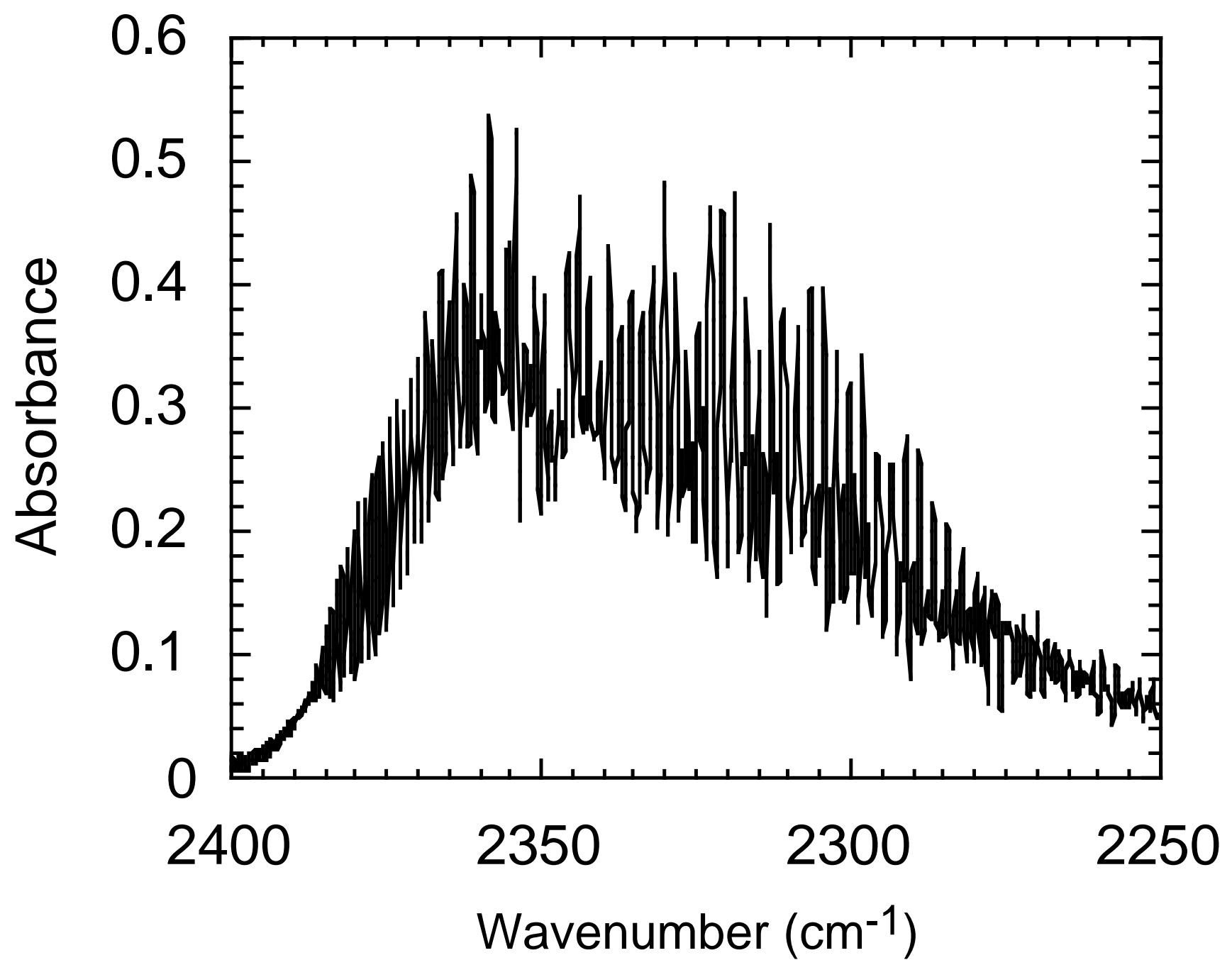

PPPL-3281/Fig. 15: FTIR spectrum of carbon dioxide antisymmetric stretching band at $2349 \mathrm{~cm}^{-1}$. 


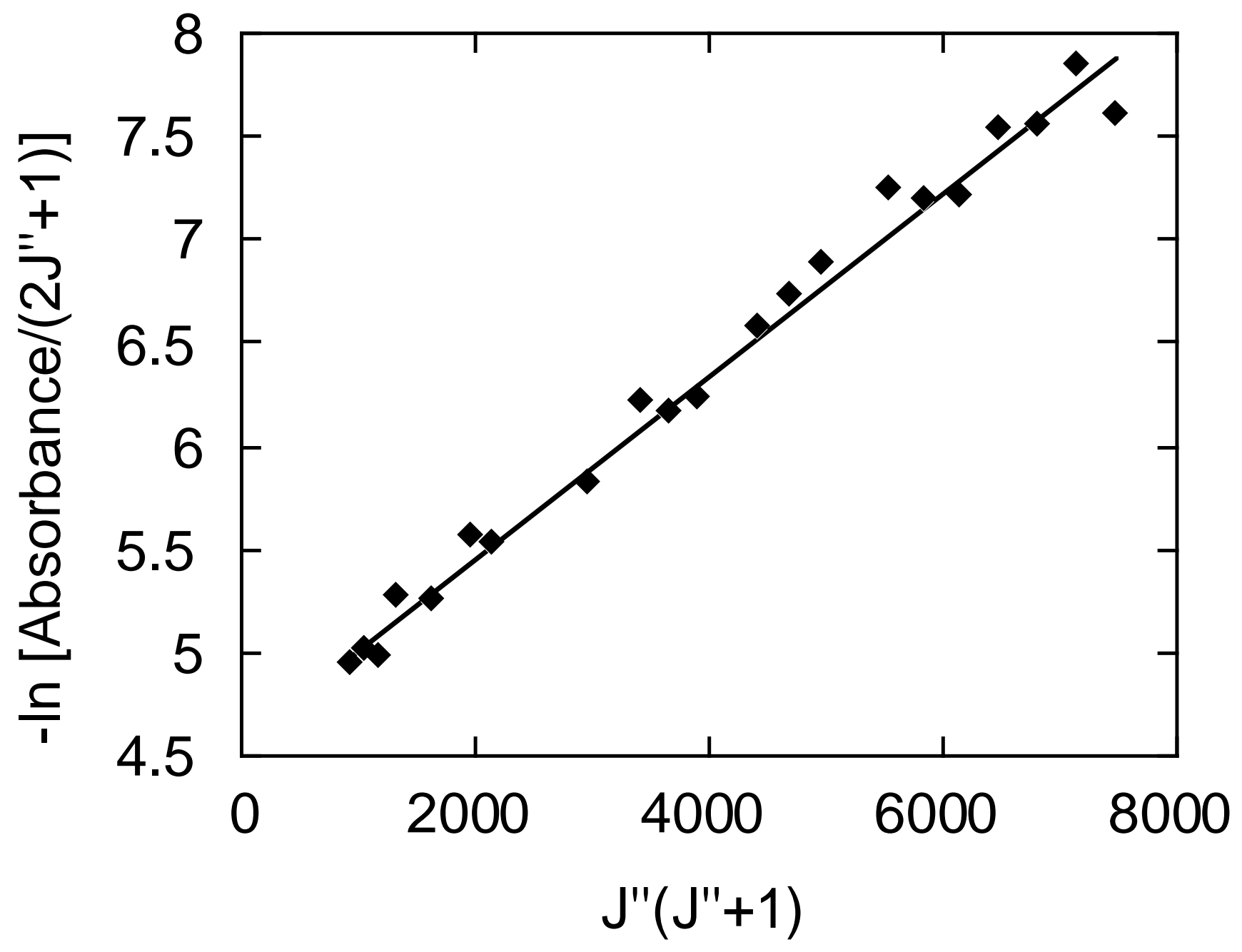

PPPL-3281/Fig. 16: Fit to carbon dioxide P-branch spectrum used to measure rotational temperature. 